\title{
Gram-negative bacteria and their lipopolysaccharides in Alzheimer's disease: pathologic roles and therapeutic implications
}

\author{
Hyeon soo Kim ${ }^{1 \dagger}$, Sujin Kim², ${ }^{1+}$, Soo Jung Shin ${ }^{1 \dagger}$, Yong Ho Park ${ }^{1 \dagger}$, Yunkwon Nam, Chae won Kim', \\ Kang won Lee ${ }^{1}$, Sung-Min Kim ${ }^{3}$, In Duk Jung ${ }^{3}$, Hyun Duk Yang ${ }^{4 *}$, Yeong-Min Park ${ }^{3,5^{*}}$ and Minho Moon ${ }^{1,2^{*}}$ (D)
}

\begin{abstract}
Alzheimer's disease (AD) is the most serious age-related neurodegenerative disease and causes destructive and irreversible cognitive decline. Failures in the development of therapeutics targeting amyloid- $\beta$ (A $\beta$ ) and tau, principal proteins inducing pathology in $A D$, suggest a paradigm shift towards the development of new therapeutic targets. The gram-negative bacteria and lipopolysaccharides (LPS) are attractive new targets for AD treatment. Surprisingly, an altered distribution of gram-negative bacteria and their LPS has been reported in AD patients. Moreover, gram-negative bacteria and their LPS have been shown to affect a variety of AD-related pathologies, such as A $\beta$ homeostasis, tau pathology, neuroinflammation, and neurodegeneration. Moreover, therapeutic approaches targeting gram-negative bacteria or gram-negative bacterial molecules have significantly alleviated AD-related pathology and cognitive dysfunction. Despite multiple evidence showing that the gram-negative bacteria and their LPS play a crucial role in AD pathogenesis, the pathogenic mechanisms of gram-negative bacteria and their LPS have not been clarified. Here, we summarize the roles and pathomechanisms of gram-negative bacteria and LPS in AD. Furthermore, we discuss the possibility of using gram-negative bacteria and gram-negative bacterial molecules as novel therapeutic targets and new pathological characteristics for AD.
\end{abstract}

Keywords: Alzheimer's disease, Gram-negative bacteria, Lipopolysaccharide, Exotoxin, Amyloid beta, Tau

\section{Introduction}

Alzheimer's disease (AD), one of the main causes of dementia, is a neurodegenerative disease causing cognitive decline and impairment of memory, language, and

\footnotetext{
*Correspondence: hyundyang@gmail.com; immun3023@kku.ac.kr; hominmoon@konyang.ac.kr

${ }^{\dagger}$ Hyeon soo Kim, Sujin Kim, Soo Jung Shin and Yong Ho Park contributed equally to this work

${ }^{2}$ Research Institute for Dementia Science, Konyang University,

Daejeon 35365, Republic of Korea

${ }^{4}$ Harvard Neurology Clinic, 294 Gwanggyojungang-ro, Suji-gu,

Yongin 16943, Republic of Korea

${ }^{5}$ Department of Immunology, School of Medicine, Konkuk University,

268, Chungwondaero, Chungju-si, Chungcheongbuk-do, Republic of Korea

Full list of author information is available at the end of the article
}

attention [1]. Previous studies have demonstrated that amyloid- $\beta(A \beta)$ and tau are pathological hallmarks and primary causes of $\mathrm{AD}$ [2]. Medications targeting $\mathrm{A} \beta$ and tau have been developed to treat AD; however, they have not been effective in clinical trials. Therefore, changes in therapeutic targets are required, and upstream pathogenic contributors that affect $A \beta$ and tau pathology are receiving increasing interest [3-5]. Many studies regarding the relationships between microbes and $\mathrm{AD}$ have indicated microorganisms as one of the new therapeutic targets for AD [6-8]. Namely, extensive changes in the microbiome occur in $\mathrm{AD}$, and studies analyzing the intestinal microbiome in $\mathrm{AD}$ patients and animal models have provided interesting insights $[9,10]$.

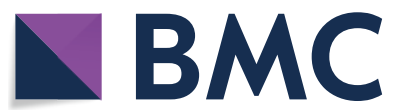

(c) The Author(s) 2021. Open Access This article is licensed under a Creative Commons Attribution 4.0 International License, which permits use, sharing, adaptation, distribution and reproduction in any medium or format, as long as you give appropriate credit to the original author(s) and the source, provide a link to the Creative Commons licence, and indicate if changes were made. The images or other third party material in this article are included in the article's Creative Commons licence, unless indicated otherwise in a credit line to the material. If material is not included in the article's Creative Commons licence and your intended use is not permitted by statutory regulation or exceeds the permitted use, you will need to obtain permission directly from the copyright holder. To view a copy of this licence, visit http://creativecommons.org/licenses/by/4.0/. The Creative Commons Public Domain Dedication waiver (http://creativeco mmons.org/publicdomain/zero/1.0/) applies to the data made available in this article, unless otherwise stated in a credit line to the data. 
Various sources of infection, such as fungi, viruses, and bacteria, are reportedly associated with AD [7]. The occurrence of microbiome dysbiosis or infection of several species of toxic bacteria may contribute to $\mathrm{AD}$ pathogenesis by triggering strong inflammatory responses or participating in $A \beta$ production $[11,12]$. Surprisingly, systemic inflammatory responses due to bacterial infection may also continue, causing neuronal cell death and $\mathrm{A} \beta /$ tau accumulation, contributing to the development and progression of $\mathrm{AD}$. The brains of $\mathrm{AD}$ patients contain 5-10 times more bacteria than healthy brains; differences in the distribution and composition of the bacteria have also been studied [13]. In addition, it has been reported that the gram-negative bacteria can cross the bloodbrain barrier (BBB) and contribute to neuroinflammation, $A \beta$ accumulation, and tau hyperphosphorylation within the brain [14]. In particular, several gram-negative bacteria, such as Proteobacteria and Chlamydophila pneumonia, have been reported to provoke strong systemic inflammation and contribute to AD pathogenesis $[15,16]$. Furthermore, the byproducts of gram-negative bacteria, such as lipopolysaccharides (LPS), capsular proteins, fimbrillins and flagellins, can also penetrate the brain and affect neuroinflammation, and $A \beta$ and tau pathology [17].

LPS is a macromolecule mainly distributed in the outer membrane of gram-negative bacteria and acts as a powerful endotoxin [18]. The immune system responds with high sensitivity to LPS, high concentrations of which can cause sepsis and septic shock [19]. Furthermore, sepsis caused by LPS is a risk factor for cognitive impairment and AD development $[20,21]$. Interestingly, LPS concentration in the plasma of patients with AD is 3-6 times higher than normal; similarly, LPS concentration in the blood of $\mathrm{AD}$ animal models is approximately 3 times higher than normal $[18,22,23]$. In AD, the LPS-induced pro-inflammatory immunomodulation is suggested to have a fatal effect on AD pathology [24]. Furthermore, a vicious cycle involving infectious species and their products in the induction of AD pathology has been continually proposed as an 'infection hypothesis' that potentially provides interesting insights into AD pathology [5, 17, 25]. These pieces of evidence suggest that LPS could not only be one of the upstream pathologic processes that either initiate or induce AD pathology, but also a promising therapeutic target for AD treatment.

Despite accumulating evidence on the importance of gram-negative bacteria and their LPS in AD pathology, their pathogenic mechanisms have not been clarified. Therefore, we attempted to summarize the pathogenic roles of gram-negative bacteria and their LPS in AD pathology and discuss their potential as effective therapeutic targets for $\mathrm{AD}$ (Additional file 1: Fig. S1).

\section{Pathomechanisms of gram-negative bacteria in AD} Alteration of gram-negative bacteria in AD

With a growing interest in the importance of intestinal bacteria in $\mathrm{AD}$ pathology, an increasing number of studies have found links among gut microbiota, infectious microbes, and $\mathrm{AD}$ pathogenesis. Particularly, gram-negative bacteria are associated with the onset of AD. Various studies have demonstrated a positive association between gram-negative bacteria, such as Helicobacter pylori (H. pylori), Porphyromonas gingivalis ( $P$. gingivalis), Prevotella melaninogenica, and Campylobacter rectus, and incidence of $\mathrm{AD}$ [26-30]. Moreover, some studies showed that the presence of gram-negative bacteria is directly associated with AD mortality [27, $30,31]$. Surprisingly, there are many studies pointing to the changes in gram-negative bacterial composition in animal models and patients with $\mathrm{AD}$ (Tables 1 and 2). In 8-month-old amyloid precursor protein/presenilin 1 (APP/PS1) mice, the proportion of Bacteroidetes at the phylum level increases, while Allobaculum and Akkermansia decrease at the genus level; concurrently, there is an increase in Rikenellaceae and S24-7 [32] (Table 1). In addition, another study demonstrated that Helicobacteraceae and Desulfovibrionaceae at the family level are significantly higher in APP/PS1 mice than in wild-type (WT) mice [33]. At the genus level, Helicobacter and Odorivacter are significantly abundant in APP/PS1 mice, while Prevotella abundance is remarkably higher in WT mice. In APP/PS1 mice, the proportion of Bacteroidetes tends to increase as $\mathrm{AD}$ progresses [34]. In the case of $5 \times$ FAD mice, it has been confirmed that the distribution of intestinal gram-negative bacteria starts to change at 9 weeks compared to that in WT mice. The proportion of Bacteroidetes in $5 \times$ FAD mice tends to decrease at 9-week-old and 18-week-old compared to 3-week-old in $5 \times$ FAD mice. These results indicated that the proportion of gram-negative bacteria changes with $\mathrm{AD}$ progression in $5 \times \mathrm{FAD}$ mice [35]. Furthermore, it is known that the distribution of intestinal gram-negative bacteria in healthy individuals differs from that in AD patients, and the distribution of intestinal gram-negative bacteria changes as $\mathrm{AD}$ progresses. Some analyses of microorganisms in blood and feces showed that patients with AD have changed populations of gram-negative bacteria, such as Spirochetes, Chlamydia, Proteobacteria, Firmicutes, Bacteroidetes, and Actinobacteria at the phylum level (Table 2). In particular, it has been confirmed that the population of Firmicutes and Bifidobacterium decreases and the population of Bacteroidetes increases in the feces of patients with $\mathrm{AD}$, compared with healthy controls [9]. Surprisingly, gram-negative bacteria found in the peripheral nervous system have also been observed in the central nervous system (CNS) in patients with 
Table 1 Species of gram-negative bacteria exhibiting alteration in animal models of Alzheimer's disease

\begin{tabular}{|c|c|c|c|c|c|c|c|c|c|}
\hline \multirow[t]{2}{*}{ Source } & \multirow[t]{2}{*}{ Subject } & \multirow[t]{2}{*}{ Method } & \multicolumn{6}{|c|}{ Gram-negative bacteria } & \multirow[t]{2}{*}{ References } \\
\hline & & & Phylum & Class & Order & Family & Genus & Species & \\
\hline \multirow[t]{14}{*}{ Feces } & \multirow[t]{8}{*}{ APP/PS1 mice } & \multirow[t]{2}{*}{$P C R$} & Proteobacteria & & & $\begin{array}{l}\text { Helicobacteraceae } \\
\text { Desulfovibrion- } \\
\text { aceae }\end{array}$ & Helicobacter & & [33] \\
\hline & & & Bacteroidetes & Bacteroidia & Bacteroidales & $\begin{array}{l}\text { Porphyromonoad- } \\
\text { aceae }\end{array}$ & Odoribacter & & \\
\hline & & PCR & Bacteroidetes & & & & & & [50] \\
\hline & & \multirow[t]{4}{*}{ PCR } & Bacteroidetes & & & & & & [32] \\
\hline & & & Bacteroidetes & Bacteroidia & Bacteroidales & Rikenellaceae & & & \\
\hline & & & Bacteroidetes & Bacteroidia & Bacteroidales & S24-7 & & & \\
\hline & & & Verrucomicrobia & Verrucomicrobiae & Verrucomicrobiales & Akkermansiaceae & Akkermansia & & \\
\hline & & PCR & Bacteroidetes & & & & & & [34] \\
\hline & \multirow[t]{4}{*}{$5 \times$ FAD mice } & \multirow[t]{2}{*}{ PCR } & Proteobacteria & $\begin{array}{l}\delta-, \gamma- \\
\varepsilon-\text { Proteobacteria }\end{array}$ & & $\begin{array}{l}\text { Helicobacte- } \\
\text { riaceae, Pseu- } \\
\text { domonadaceae }\end{array}$ & & & [23] \\
\hline & & & Bacteroidetes & Bacteroidia & Bacteroidia & Prevotellaceae & & & \\
\hline & & $P C R$ & Bacteroidetes & & & & & & [35] \\
\hline & & PCR & Bacteroidetes & Bacteriodia & Bacteroidales & Muribaculaceae & & & [10] \\
\hline & \multirow{2}{*}{$\begin{array}{l}5 \times \text { FAD mice } \\
3 \times \text { Tg mice }\end{array}$} & \multirow[t]{2}{*}{ PCR } & Bacteroidetes & & & & & & [51] \\
\hline & & & Proteobacteria & & & & & & \\
\hline
\end{tabular}

$P C R$ Polymerase chain reaction

AD [13, 36-39]. The gram-negative bacteria that show changes in the proportion and population within the brain and cerebrospinal fluid (CSF) of patients with $\mathrm{AD}$ are Chlamydia, Proteobacteria, Bacteroidetes, and Spirochetes $[13,15,38,40-49]$. These results suggest that the gram-negative bacteria in the peripheral system can penetrate the $\mathrm{BBB}$ and infiltrate the brain.

Interestingly, the gram-negative bacteria penetrate the $\mathrm{BBB}$ and affect the brain through four potential mechanisms (Fig. 1). First, gram-negative bacteria disrupt the intercellular junctions and induce endothelial cell detachment using their adhesin, pili, and fimbria, allowing them to penetrate the BBB through the paracellular pathway [54]. For instance, the pilus-mediated signaling events promote alterations in tight junction organization. Escherichia coli (E. coli) binds to brain microvascular endothelial cell receptors to trigger the release of interleukin (IL)- 6 and IL-8, and production of inducible nitric oxide synthase (iNOS), and at the meantime breaks down tight junctions between endothelial cells to aggravate BBB disruption [54]. Second, gram-negative bacteria can penetrate the BBB and enter the brain through necrosis of endothelial cells caused by exotoxins, such as hemolysin and protease. Injection of heme carrier protein 1, a component of the Type VI secretion system of $E$. coli $\mathrm{K} 1$, into the cytoplasm of human brain endothelial cells induces necrosis of endothelial cells [55]. Third, gram-negative bacteria internalize into the $\mathrm{BBB}$ through transcytosis via interactions between bacterial outer membrane proteins and endothelial cells $[55,56]$. The E. coli $\mathrm{K} 1$ promotes bacterial transcytosis across the endothelium through outer membrane protein A (OmPA), invasion of the brain endothelium protein (IbeA), endothelial receptors beta-form of the heat-shock gp96 (Ecgp96), and contactin-associated protein 1 . The gram-negative bacteria that enter the brain through transcytosis can survive and proliferate by reducing or escaping from the immune response. Finally, the gramnegative bacteria can enter the CNS through the cranial nerves. In particular, the trigeminal and olfactory nerves are suggested as major paths for oral bacteria to enter the brain [57], with several gram-negative oral bacteria capable of affecting the CNS through these neural tracts [58]. Studies using BALB/c mice and the AD model showed that oral bacteria migrate to the brain at a very high frequency through the cranial nerve [59,60]. Furthermore, it has been reported that DNA of $P$. gingivalis, which is a gram-negative oral anaerobe involved in the pathogenesis of periodontitis, is characteristically detected in the brains and CSF of patients with $\mathrm{AD}$ [59]. In addition, $H$. pylori, a gram-negative bacterium, can enter the CNS through the oral-nasal-olfactory pathway or the gastrointestinal tract-brain neural pathway [61]. These studies support the hypothesis that the gram-negative bacteria can directly penetrate the brain. In this respect, the 


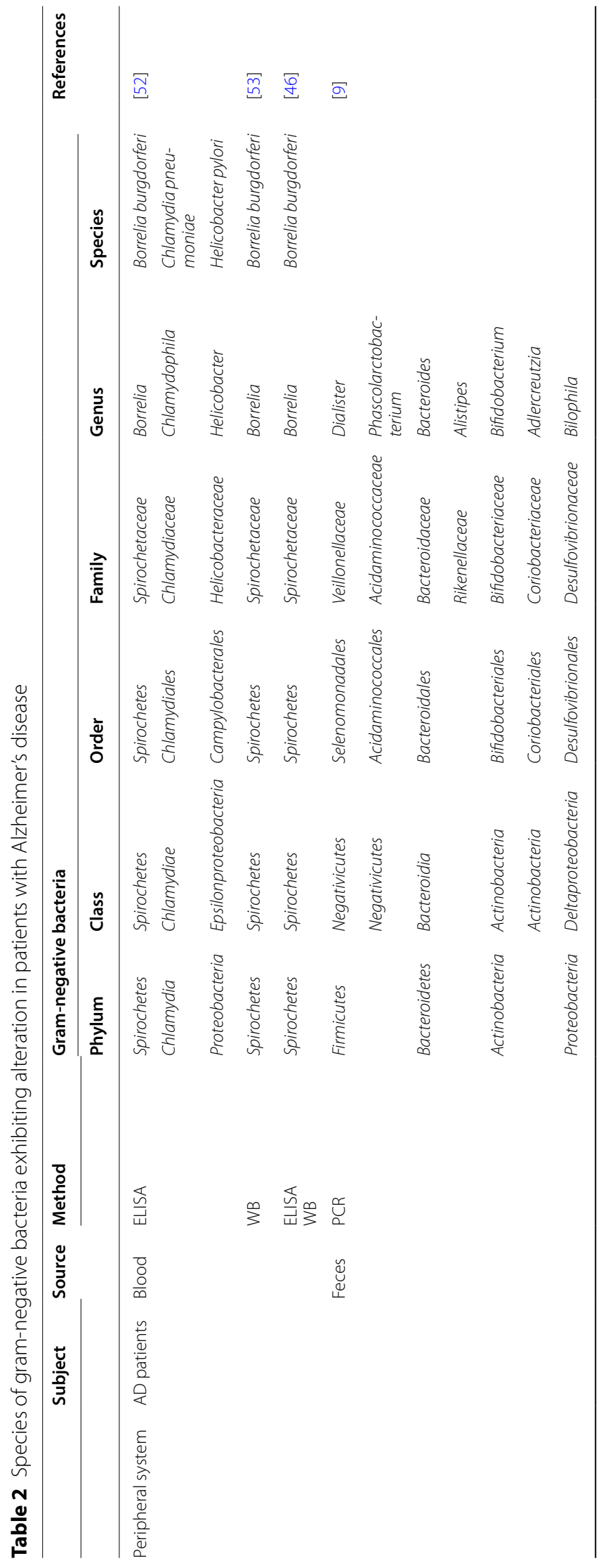




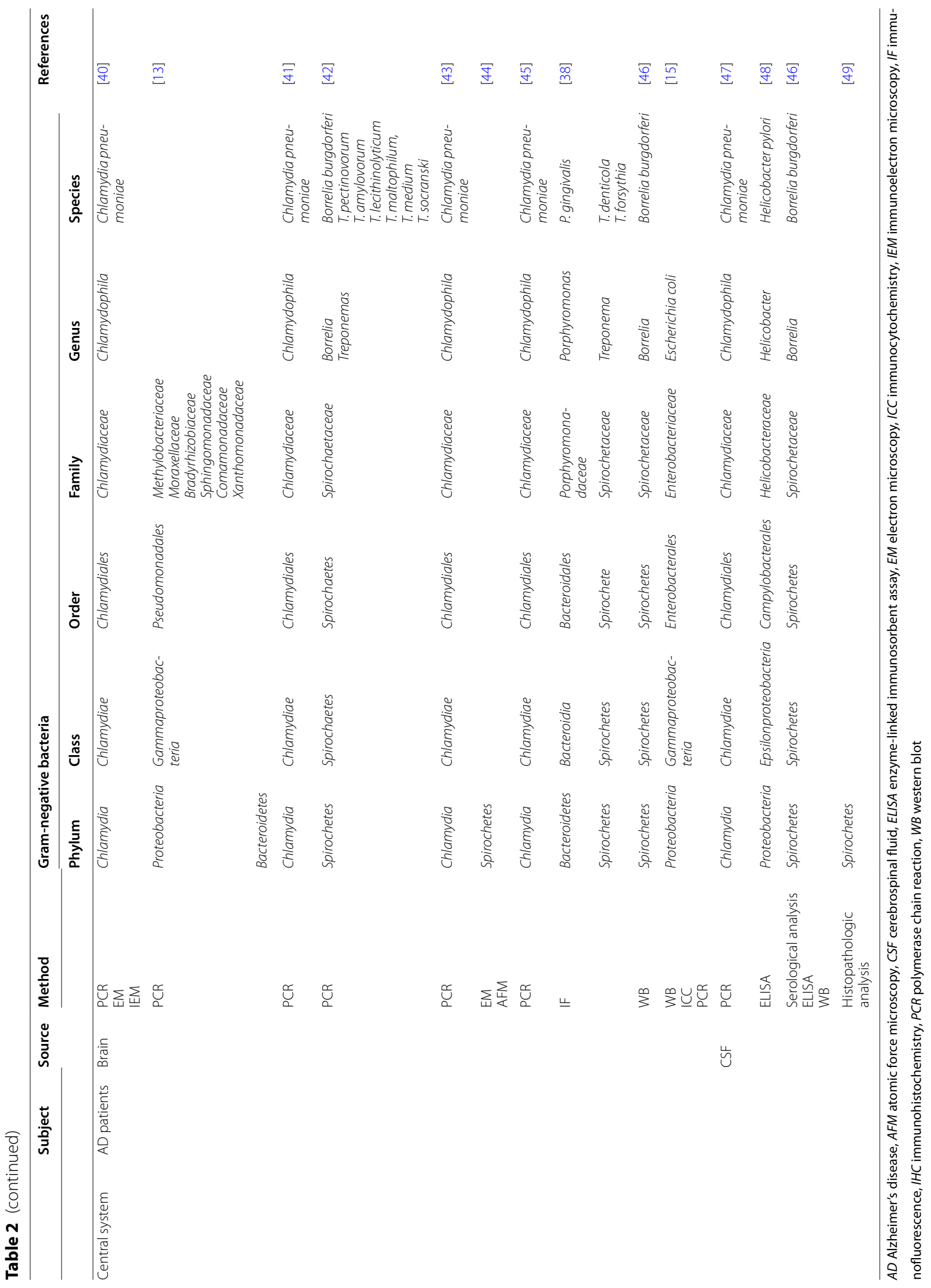


gram-negative bacteria penetrating the $\mathrm{BBB}$ can affect the onset or progression of $\mathrm{AD}$.

\section{Possible roles of gram-negative bacteria in AD pathogenesis Microbiota dysbiosis}

Under healthy conditions, most intestinal microbiomes interact with the brain through several mechanisms, including neurotransmitter generation, and contribute to the maintenance of brain homeostasis [62]. Increasing evidence suggests that the gastrointestinal tract is the bridge between the microbiota and the CNS [63]. The link between the microbiome and brain disorders emerged from the impact of gastrointestinal microbes on the development of microbial byproducts in the brain [64]. The microbial-derived byproducts are active mediators of gut-brain communication and may be potential therapeutic targets for neurodevelopmental and neurodegenerative disorders. Particularly, bacterial byproducts and exotoxin molecules, such as capsular proteins, flagellin, short-chain fatty acids (SCFA), fimbrillin, peptidoglycan, proteases, gingipain, vacuolating cytotoxin A (VacA), and methylglyoxal (MG), may be considered pathogen-associated molecular patterns. Moreover, exotoxins interact with pattern recognition receptors, such as toll-like receptors (TLR) 2 and 4. Thus, bacteria imbalance and gut exotoxins induce neuroinflammatory reactions, such as microglial cell activation, affecting the function of neuronal cells [65]. The dysregulated microbiota-induced inflammation may also lead to the invasion of microbes or microbial byproducts into the brain, neuroinflammation, and production of $A \beta$ and phosphorylated tau [66]. One study reported that alterations of the composition of gut microbiota in APP/PS1 mice are related to the increased $A \beta$ levels in the brain and impairment of cognitive function. Moreover, another study found that the dysregulation of microbiota, intestinal epithelial barrier dysfunction, and vascular $A \beta$ deposition occur in the intestine before the onset of cerebral A $\beta$ deposition in Tg2576 mice [67]. These reports suggest that microbiota dysregulation is related to the development and progression of $\mathrm{AD}$.

\section{A $\beta$ homeostasis}

The precipitate, which shows a $\beta$-folded sheet structure located vertical to the fibrous axis and is rich in aggregated insoluble lipoproteins, was designated as amyloid. Because of the hydrophobic nature of the aromatic amino acid peptides that compose the primary sequence of APP-derived amyloid, self-aggregation of amyloid monomers compiles over time into dimers, oligomers, and fibrils. Significant inflammatory reactions and neurodegeneration from amyloid accumulation appear in the brain, which affects neurodegenerative diseases, such as AD, Parkinson's disease, and prion disease [68]. Surprisingly, many studies have revealed the presence of bacteria-produced amyloids [68-70] (Fig. 2). The bacterial amyloids have a biophysical nature that is highly similar to human-derived amyloids, including the aggregateforming ability [71, 72]. Although the amyloid produced by bacteria differs in its primary structure from the amyloid produced in the CNS, they have similarities in their tertiary structure [73]. Exposure to bacterial amyloid proteins in the gut could provoke systemic inflammation [74]. Moreover, bacterial amyloid affects disease progression by interacting with $\mathrm{A} \beta$ present in the $\mathrm{AD}$ brain (Table 3). The interaction of bacterial amyloid with neuronal amyloid, which is endogenously produced in the brain, promotes either their aggregation or cross-seeding in the AD brain [75, 76]. Furthermore, bacterial amyloid significantly promotes $\mathrm{A} \beta$ pathology in AD [69]. Curli is a well-known gram-negative bacterial amyloid. It is an integral part of the biofilm extracellular matrix produced by certain strains of enterobacteria, such as E. coli [77]. CsgA and CsgB are not only two major structural components of curli fibers, but are also essential components of biofilms [78]. In particular, the structure of the fibril produced by CsgA and CsgB of curli proteins is very similar to that of amyloid [79]. Interestingly, the fibril includes a $\beta$-sheet structure similar to $A \beta$ and has been reported to form fibrillar aggregates [80]. The bacterial amyloid from curli may be a potential contributor to $A \beta$ pathology in $\mathrm{AD}$ since several amyloid proteins interact with $\mathrm{A} \beta$ to induce co-aggregation or cross-seeding $[37,75]$. In addition, FapC, a bacterial amyloid from Pseudomonas, is another strong contributor to $A \beta$ pathology [81]. The FapC fibril is a powerful accelerator of $A \beta$ fibrillization in $\mathrm{AD}$ [82]. In the co-culture of $\mathrm{A} \beta$ and FapC seeds, the rate of increase of the $\beta$-sheet ratio was more than three times above the A $\beta$-only culture [82]. Furthermore, FapC has been reported to promote $A \beta$-associated pathology several times faster in the AD zebrafish model [82]. Surprisingly, the bacterial amyloid and $A \beta$ can bind to the same receptor due to their structural similarity. For example, similar to $A \beta$, the bacterial amyloid from curli can bind to the TLR2-TLR1-CD14 (cluster of differentiation 14) complex, which facilitates the nuclear factor kappa-lightchain-enhancer of activated B cells $(\mathrm{NF}-\mathrm{kB})$ pathway [83]. Moreover, MG, an intermediate metabolite of glucose metabolism in cells, is widely secreted by gram-negative bacteria such as E. coli, and distributed at a high rate in the body [84]. The MG acts as a ligand for the receptor for advanced glycation end products (RAGE), resulting in increased beta-site amyloid precursor protein cleaving enzyme 1 (BACE-1) expression and $A \beta$ levels $[85,86]$. 


CNS
Fig. 1 Mechanisms of gram-negative bacteria penetration to the central nervous system. (1) The gram-negative bacteria-derived exotoxins
provoke detachment of endothelial cells, and the gram-negative bacteria-induced inflammatory cytokines induce disruption of the tight junction
at the blood-brain barrier (BBB). These impairments of BBB allow the gram-negative bacteria to pass through the brain in the paracellular pathway.
(2) The gram-negative bacteria-derived exotoxins directly influence endothelial necrosis. (3) The gram-negative bacteria are transported to the
brain via vesicular transport of macromolecules, such as outer membrane protein A (OmPA), invasion of the brain endothelium protein A (IbeA),
endothelial receptors beta-form of the heat-shock gp96 (Ecgp96), and contactin-associated protein 1 (CaspR1). (4) The cranial nerve can be a
pathway for gram-negative bacteria to enter the brain without penetrating the BBB. CNS: Central nervous system; iNOS: Inducible nitric oxide
synthase; PNS: peripheral nervous system

In addition, it has been shown that $P$. gingivalis increases $A \beta$ production by increasing the gene expression of APP and BACE1 and decreasing the gene expression of disintegrin and metalloproteinase domain-containing protein 10 (ADAM10) [59, 87]. Moreover, gingipain, a family of proteases secreted by $P$. gingivalis, can affect to activate $\gamma$-secretase through cleavage of caspase-3 [87]. In addition, three proteinase genes that contribute to the virulence of $P$. gingivalis, $\operatorname{Rgp} A$, $\operatorname{RgpB}$, and $K g p$, have been associated with $A \beta$ production. In particular, $\operatorname{Rgp} B$ has been reported to induce massive generation of $A \beta$ by activating the metalloproteinase meprin $\beta$, which is an alternative BACE1 cleavage of APP [88]. Furthermore, the load of $\mathrm{KgpB}$ is particularly increased in the $\mathrm{AD}$ brain compared to the healthy brain, and RgpB has been reported to co-localize with $A \beta$ [59]. Collectively, these findings suggest that bacterial molecules from gram-negative bacteria could induce the production and aggregation of $\mathrm{A} \beta$, affecting the onset and progression of $\mathrm{AD}$.

\section{Tau pathology}

Hyperphosphorylated tau aggregation is the main pathological hallmark of AD [98]. Neurofibrillary tangles (NFTs) consist of hyperphosphorylated and aggregated microtubule-associated protein tau [99], while the intermediate form of tau causes cytotoxicity and cognitive impairment [100]. Tau hyperphosphorylation is regulated by various kinases that are affected by numerous factors, including gram-negative bacteria [101, 102] (Fig. 2). Helicobacter pylori induces tau hyperphosphorylation by activating the glycogen synthase kinase-3 $\beta$ (GSK-3 $\beta$ ) [102]. Moreover, it has been revealed that $P$. gingivalis can increase tau hyperphosphorylation at, e.g., Thr231 and Ser396 residues, in human iPSC-differentiated neuronal cells and C57BL/6 mice [87, 103]. Particularly, $P$. gingivalis infection activates GSK-3 $\beta$ [104]. Furthermore, gingipain can contribute to tau hyperphosphorylation by regulating the protein kinase $\mathrm{B}(\mathrm{Akt}) / \mathrm{GSK}-3 \beta$ activity by cleaving procaspase-3 to caspase-3 [59, 105]. Gingipain is involved in tau fragmentation and generation of paired helical filament through tau proteolysis; the tau fragments can induce tau aggregation and phosphorylation [106-108] (Table 3). Interestingly, Kgp has been reported as a trigger or accelerator of tau pathology [59]. The hexapeptide motif-containing tau peptide generated by Kgp can be easily hyperphosphorylated and contribute to the formation of paired helical filaments and NFT. Similarly, MG has been reported to induce tau hyperphosphorylation through the GSK-3 $\beta$ activity [89]. Furthermore, DNA derived from several species of gram-negative bacteria, such as E. coli and P. gingivalis, has been reported to promote tau pathology [109]. In particular, the gramnegative bacterial DNA-frequently reported in patients with $\mathrm{AD}$-strongly induces tau misfolding and aggregation [109]. Therefore, gram-negative bacteria could initiate or exacerbate tau pathology by inducing tau hyperphosphorylation and aggregation in $\mathrm{AD}$.

\section{Neuroinflammation}

Neuroinflammation is a pathological hallmark induced by abnormally aggregated $\mathrm{A} \beta$ peptides in $\mathrm{AD}[110$, 111]. Moreover, microglia activated by $A \beta$ can accelerate neurodegeneration in the brain during $\mathrm{AD}$ [111]. Gram-negative bacteria are known triggering factors for inflammatory responses [112]. A study confirmed that the effect of microbiota on microglial maturation in 


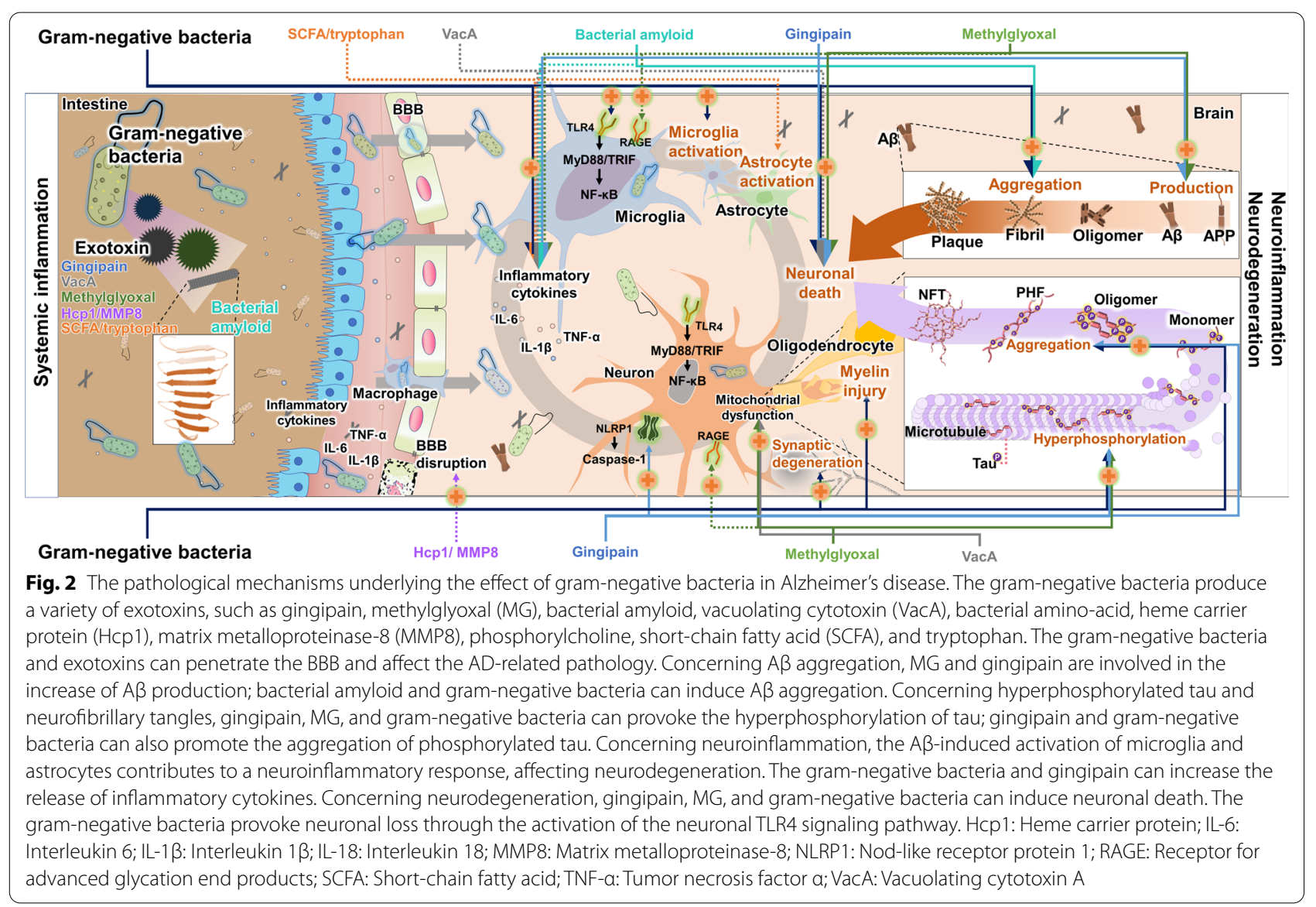

germ-free mice could be regulated by SCFA, a byproduct of bacterial metabolism [94]. Furthermore, the microbial metabolites of tryptophan can modulate astrocyte activity [97]. These results show that the bacterial-derived byproducts, such as VacA, SCFA, phosphorylcholine, and tryptophan [90, 94-97], are involved in neuroinflammation by modulating microglia and astrocyte activity. Although this evidence demonstrates the pivotal role of byproducts from gram-negative bacteria in neuroinflammation, only a few studies have investigated their effects in AD. A recent study showed that the $P$. gingivalis oral infection causes strong microglial activation in the brains of apolipotein E (ApoE) $)^{-/-}$mice [60]. In particular, gingipain from $P$. gingivalis can lead to the release of neuroinflammatory cytokines in an AD brain [59] (Fig. 2). In addition, respiratory infection of Bordetella pertussis in APP/PS1 mice increases brain infiltration of $\mathrm{T}$ cells and activation of microglia and macrophages [113]. Helicobacter pylori infection stimulates the secretion of pro-inflammatory cytokines, such as tumor necrosis factor- $\alpha$ (TNF- $\alpha)$ and IL- 6 , causing inflammation-related neurodegeneration [61]. Moreover, it has been reported that monocytes infected with Chlamydia pneumoniae
(C. pneumoniae) may contribute to late-onset $\mathrm{AD}$ by inducing secretion of pro-inflammatory cytokines and chemokines from microglia and astrocytes [114]. Furthermore, the C. pneumoniae-infected microglia show increased levels of TNF- $\alpha$ [115], a critical neuroinflammatory factor in AD. These findings imply that the gramnegative bacteria introduced into the CNS can aggravate AD pathology through strong neuroinflammation.

\section{Neuronal cell death}

Neuronal loss is a prominent pathological feature of AD [3]. Surprisingly, gram-negative bacteria, H. pylori, can induce neuronal cell death by secreting VacA [91]. Moreover, MG from gram-negative bacteria-a cell deathrelated toxin-has been reported to induce oxidative stress and apoptosis through activation of nicotinamide adenine dinucleotide phosphate oxidase and production of reactive oxygen species [64]. In AD, MG is a potential key factor that triggers neuronal death through the decrease of mitochondrial membrane potential, downregulation of $\mathrm{Bcl}-2$, and up-regulation of pro-apoptotic proteins, such as caspase- 3 and Bax [116, 117]. These mitochondrial dysfunctions caused by MG can accelerate 
Table 3 Gram-negative bacteria-derived products affect Alzheimer's disease and other diseases

\begin{tabular}{|c|c|c|c|c|c|c|c|}
\hline & \multirow{2}{*}{$\begin{array}{l}\text { Gram-negative } \\
\text { bacteria- } \\
\text { derived } \\
\text { products }\end{array}$} & \multicolumn{5}{|c|}{ AD-related pathology } & \multirow[t]{2}{*}{ References } \\
\hline & & $A \beta$ & Tau & Neuroinflammation & Cell death & BBB disruption & \\
\hline \multirow[t]{4}{*}{$\begin{array}{l}\text { In Alzheimer's } \\
\text { disease }\end{array}$} & Gingipain & Production $\uparrow$ & $\begin{array}{l}\text { Hyperphospho- } \\
\text { rylation } \uparrow \\
\text { Aggregation } \uparrow\end{array}$ & $\begin{array}{l}\text { Proinflammatory } \\
\text { cytokines } \uparrow\end{array}$ & $\begin{array}{l}\text { Pyroptosis } \uparrow \\
\text { Caspase- } 1 \uparrow\end{array}$ & & {$[59]$} \\
\hline & $\begin{array}{l}\text { Methylglyoxal } \\
\text { (MG) }\end{array}$ & Production $\uparrow$ & $\begin{array}{l}\text { Hyperphospho- } \\
\text { rylation } \uparrow\end{array}$ & & $\begin{array}{l}\text { Oxidative stress } \uparrow \\
\text { Apoptosis } \uparrow\end{array}$ & & {$[64,85,89]$} \\
\hline & Hсp1 & & & & & $\begin{array}{l}\text { Endothelial cell } \\
\text { disruption } \uparrow\end{array}$ & {$[55]$} \\
\hline & Bacterial amyloid & Aggregation $\uparrow$ & & & & & [82] \\
\hline \multirow[t]{7}{*}{ In other diseases } & VacA & & & $\begin{array}{l}\text { Proinflammatory } \\
\text { cytokines } \uparrow\end{array}$ & $\begin{array}{l}\text { Cell vacuola- } \\
\text { tion } \uparrow\end{array}$ & & {$[90,91]$} \\
\hline & $\begin{array}{l}\text { Bacterial amino- } \\
\text { acid }\end{array}$ & & & $\begin{array}{l}\text { Systemic inflamma- } \\
\text { tion } \uparrow\end{array}$ & & & [10] \\
\hline & Hcp1 & & & & & $\begin{array}{l}\text { Endothelial cell } \\
\text { disruption } \uparrow\end{array}$ & {$[55]$} \\
\hline & MMP8 & & & & & $\begin{array}{l}\text { Junctional } \\
\text { protein degrada- } \\
\text { tion } \uparrow\end{array}$ & {$[92]$} \\
\hline & $\begin{array}{l}\text { Phosphorylcho- } \\
\text { line }\end{array}$ & & & $\begin{array}{l}\text { Proinflammatory } \\
\text { cytokine } \uparrow\end{array}$ & & & [93] \\
\hline & $\begin{array}{l}\text { Short chain fatty } \\
\text { acid }\end{array}$ & & & $\begin{array}{l}\text { Proinflammatory } \\
\text { cytokine } \uparrow \\
\text { Gliosis } \uparrow\end{array}$ & & $\begin{array}{l}\text { Endothelial cell } \\
\text { disruption } \uparrow\end{array}$ & [94-96] \\
\hline & Tryptophan & & & $\begin{array}{l}\text { Proinflammatory } \\
\text { cytokine } \uparrow \\
\text { Gliosis } \uparrow\end{array}$ & & $\begin{array}{l}\text { Endothelial cell } \\
\text { disruption } \uparrow\end{array}$ & [97] \\
\hline
\end{tabular}

$A D$ Alzheimer's disease, $A \beta$ Amyloid- $\beta, B B B$ blood-brain barrier, Hcp 1 Heme carrier protein 1, MMP8 matrix meralloproteinase-8, ROS reactive oxygen species, VacA vacuolating cytotoxin

AD neurodegeneration. TLR4 activates the nod-like receptor protein 3 by recognizing gram-negative bacteria; it is a key receptor for the onset of neurodegenerative diseases, including AD [118]. Therefore, activation of TLR4 signaling by gram-negative bacteria can lead to neuronal cell death [119]. Importantly, gram-negative bacteria can trigger neuronal cell death through not only their byproducts but also the bacteria themselves (Fig. 2). Taken together, both gram-negative bacteria and their byproducts could play a key role in neuronal cell death and neurodegeneration in AD.

\section{Specific roles of LPS from gram-negative bacteria in AD}

Peripheral and central localization of LPS in AD

Most LPS is produced by intestinal gram-negative bacteria; subsequently, it can escape the intestine and enter the circulatory system [120]. The high concentration of LPS can induce TLR4-dependent CD14 upregulation in enterocytes, thereby damaging the intestinal epithelial barrier and increasing the gut permeability. Surprisingly, one study reported that the LPS level in the plasma is increased 3-6 times in $\mathrm{AD}$ patients $(61 \pm 42 \mathrm{pg} / \mathrm{ml})$ compared to that in healthy controls $(21 \pm 6 \mathrm{pg} / \mathrm{ml})$ [22]. Such changes could be associated with an increased permeability induced by LPS in the intestine [121, 122]. This suggests that, as AD increases, the intestinal epithelial barrier may have an increased permeability to intestinal LPS, which leads to the spread of LPS throughout the body.

Surprisingly, several previous studies have shown an extensive and characteristic distribution of LPS in the AD brain (Table 4). LPS localization has been reported in various regions, such as the lateral ventricle of the parietal lobe and neocortex of the temporal lobe of the AD brain, suggesting that it can be widely distributed in AD brains [38, 123-125]. The mechanisms by which LPS crosses the BBB have not yet been clearly elucidated; however, several mechanisms have been proposed. First, LPS binds to the lipopolysaccharide-binding proteins (LBP) and can pass the $\mathrm{BBB}$ using receptors distributed within the $\mathrm{BBB}$, such as scavenger receptor class B type I, apolipoprotein A-I and ApoE, and apolipoprotein E receptor 2 (ApoER2) [126] (Fig. 3). Second, LPS can be transported through phagocytosis by peripheral immune cells. In particular, LPS stimulation increases both the secretion 
of peripheral and central inflammatory cytokines and the expression of adhesion molecules in BBB endothelial cells, such as p-selectin, intercellular adhesion molecules-1, and vascular cell adhesion molecules-1, which potentially increases immune cell entry into the BBB [127-130]. Third, it has been suggested that high LPS doses induce a pro-inflammatory response, destroying the BBB and allowing LPS to enter the CNS [131]. For instance, either LPS or LPS-induced TNF- $\alpha$ can degrade glycocalyx in the endothelial cells of the $\mathrm{BBB}$, thereby increasing the BBB permeability [132]. Fourth, LPS entry into the $\mathrm{BBB}$ could occur without mediation, by binding to the CD14/TLR4 complex on BBB endothelial cells [126]. Fifth, another interesting possibility is that the LPS molecules not only pass directly through the BBB [133] but also enter the brain through gram-negative bacteria [134], which are capable of transferring both exotoxins and endotoxins to the host cells through outer membrane vesicles (OMVs) [135]. An OMV is a bacterial transporter capable of entering various cell types, such as gut and BBB endothelial cells. Therefore, LPS can be introduced into neuronal cells through the OMV-containing LPS, derived from gram-negative bacteria. It is well established that the OMV-delivered LPS induces a stronger physiological response than pure LPS [135]. Therefore, LPS transmitted through gram-negative bacteria in the brain, can be more harmful to neuronal cells. Moreover, it is possible that LPS can accumulate in neuronal cells [124]. Taken together, LPS could sufficiently contribute to $\mathrm{AD}$ pathology through various $\mathrm{BBB}$ penetration mechanisms.

\section{Pathogenic contribution of LPS to AD-related pathology $A \beta$ homeostasis}

$A \beta$ accumulation is significantly reduced in sterile APP mice, but consistently increased in LPS-treated APP mice $[32,137]$, highlighting the role of LPS, apart from established AD pathogenic factors, and presenting LPS as a potential risk factor, equally strong as AD's genetic components. LPS modulates $A \beta$ production by significantly increasing the activity of APP-cleaving enzymes, such as BACE- 1 and $\gamma$-secretase, while decreasing $\alpha$-secretase activity [138] (Fig. 4). Moreover, LPS increases mRNA expression of APP and contributes to the production of $\mathrm{A} \beta$ in the hippocampus through the cathepsin B-related mechanism [139]. In LPS-injected rodents, BACE1 immunoreactivity and $A \beta$ accumulation were found in the ipsilateral cerebral cortex and hippocampal formations [140]. Moreover, LPS increases A $\beta$ oligomers by promoting $A \beta$ aggregation [18, 141]. Furthermore, the LPS-induced systemic inflammation could provoke $A \beta$ clearance impairment via (1) down-regulated expression of low-density lipoprotein receptor-related protein 1
(LRP-1); (2) inhibition of $A \beta$ entry into the blood vessels in the brain; and (3) dysfunction of p-glycoprotein [142]. These studies demonstrate that the LPS-induced A $\beta$ burden and $A \beta$ plaques could play key roles in $A \beta$-related AD pathology.

\section{Tau pathology}

LPS is potentially instrumental in exacerbation of tau pathology (Fig. 4). First, LPS induces tau phosphorylation through not only hypoactivation of tau phosphatase but also activation of cyclin-dependent kinase 5 (CDK-5) and GSK- $3 \beta[143,144]$. LPS may stimulate the activation of GSK-3 $\beta$ through regulating the phosphoinositide3-kinase (PI3K)/Akt pathway, increasing the production of phosphorylated tau [104, 145]. In particular, LPS can increase phosphorylation of tau in the hippocampus $[144,146,147]$. Second, LPS induces tau aggregation in the AD brain [143]. Several studies have reported that LPS contributes to the tau aggregation through activation of CDK- 5 and GSK-3 $\beta$ in the $3 x$ Tg model $[143,144]$. Accumulating evidence suggests that LPS accelerates tau pathology by acting as an exogenous regulator of kinases such as mitogen-activated protein kinase (MAPK), GSK-3 $\beta$, c-Jun N-terminal kinases, and p38 [143, 148]. These results suggest that LPS may affect tau pathology by inducing hyperphosphorylation and aggregation of tau. Moreover, LPS could play a key role in tau hyperphosphorylation and aggregation, which is considered a major factor and therapeutic target for AD pathology.

\section{Neuroinflammation}

Accumulating evidence suggests that LPS contributes to $\mathrm{AD}$ pathology through glial activation modulation (Fig. 4). It has been reported that LPS administration increases microglial density in the brain [141]. In particular, LPS is an agonist of glial TLR4, activating the myeloid differentiation primary response 88/toll/interleukin-1 receptor-domain-containing adapter-inducing interferon- $\beta$ (MyD88/TRIF) pathway and promoting pro-inflammatory responses by activating NF- $\mathrm{kB}$ [149151]. In contrast, some studies have suggested that LPS promotes the anti-inflammatory response [152, 153]. It has been proposed that continuous mild LPS exposure reduces inflammatory responses in the brain by suppressing pro-inflammatory mediators and boosting anti-inflammatory mediators [152]. In addition, several studies have revealed that low-dose LPS can induce anti-inflammatory responses in $\mathrm{AD}$ animal models [154-156]. The possible underlying mechanism is that the low-dose LPS exposure reduces inflammation via upregulating the expression of MyD88-dependent signaling pathway inhibitors like IRAK-M, Ship, and Tollip [157]. Unfortunately, the precise mechanism by which 
Table 4 Localization and change of lipopolysaccharides in Alzheimer's disease

\begin{tabular}{|c|c|c|c|c|}
\hline Source & Subject & Method & Main findings & References \\
\hline \multirow[t]{6}{*}{ Brain } & AD patients & Immunoblot & LPS was detected in the area adjacent to the lateral ventricle of the parietal lobe of AD brain & [38] \\
\hline & AD patients & $\begin{array}{l}\text { WB } \\
\text { IHC }\end{array}$ & $\begin{array}{l}\text { LPS was detected in temporal lobe neocortex perinuclear region of AD brain } \\
\text { LPS was co-localized with A } \beta \text { plaque }\end{array}$ & [125] \\
\hline & AD patients & $\begin{array}{l}\text { IF } \\
\text { WB }\end{array}$ & $\begin{array}{l}\text { LPS was detected in superior temporal gyrus gray matter, frontal lobe white matter, and } \\
\text { periventricular white matter of AD brain } \\
\text { LPS was localized with A } \text { plaque, neurons, microglia, and oligodendrocytes }\end{array}$ & [15] \\
\hline & AD patients & $\mathrm{IHC}$ & $\begin{array}{l}\text { LPS was detected in superior temporal lobe neocortex of AD brain } \\
\text { LPS was localized in neurons }\end{array}$ & [124] \\
\hline & AD patients & WB & LPS was detected in temporal lobe neocortex and hippocampus of AD brain & [123] \\
\hline & $5 \times F A D$ mice & IF & $\begin{array}{l}\text { LPS was detected in pyramidal and stratum oriens regions of hippocampus of AD brain } \\
\text { LPS was co-localized with LPS-phagocytic cell }\end{array}$ & [23] \\
\hline \multirow[t]{3}{*}{ Blood } & AD patients & LAL assay & LPS levels in AD patients were 3- to 6-fold compared with that in control & [22] \\
\hline & $5 \times$ FAD mice & ELISA & LPS levels in AD mice were 4-fold compared with that in control & [23] \\
\hline & $5 \times$ FAD mice & LAL assay & LPS levels in AD mice were 4-fold compared with that in control & [136] \\
\hline Feces & $5 \times F A D$ mice & LAL assay & LPS levels in AD mice were 3- to 4-fold compared with that in control & {$[23,136]$} \\
\hline
\end{tabular}

$A D$ Alzheimer's disease, ELISA Enzyme-linked immunosorbent assay, IF immunofluorescence, IHC immunohistochemistry, LAL assay limulus amebocyte lysate assay, LPS lipopolysaccharides, WB western blot

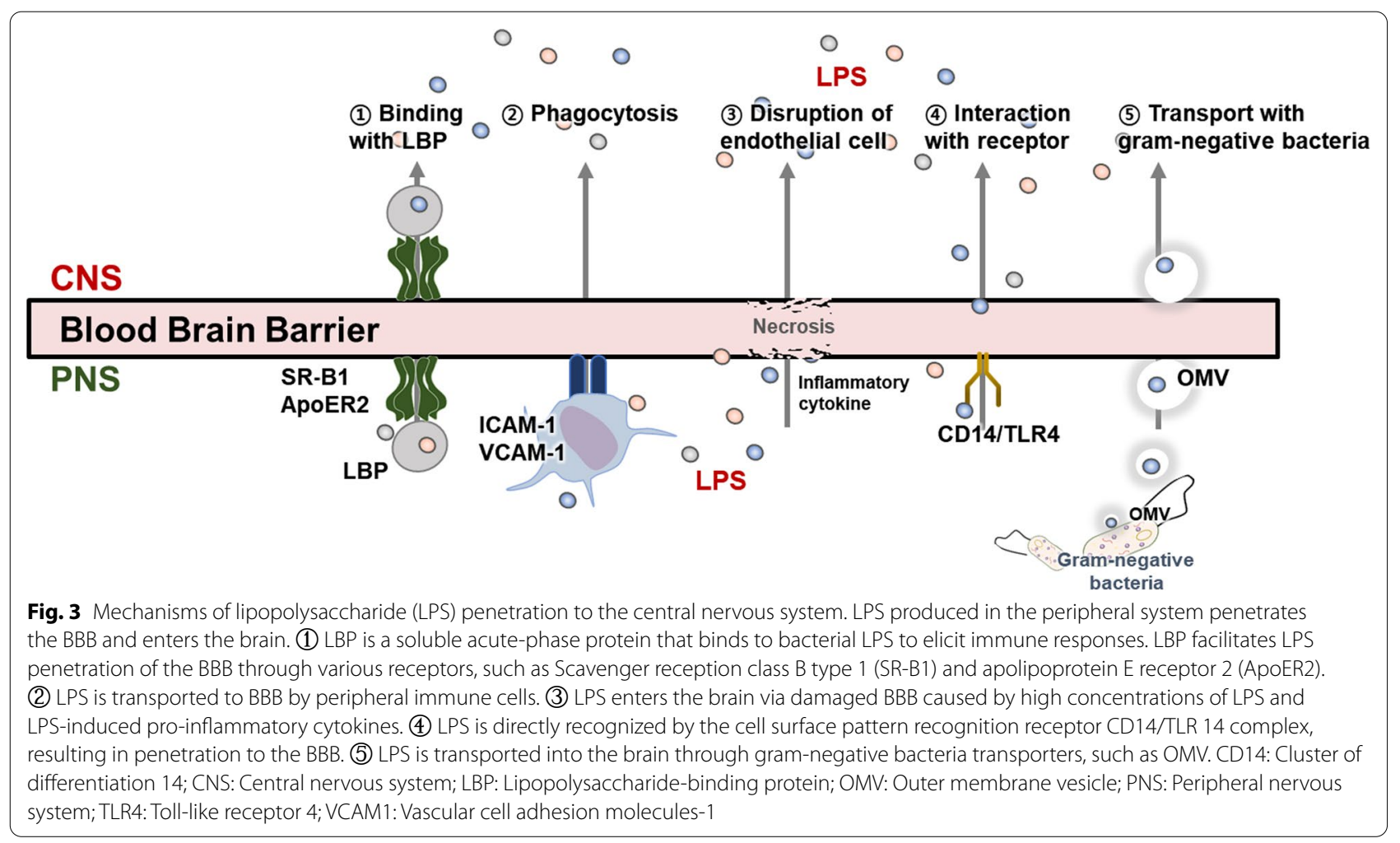

mild LPS exposure provokes the anti-inflammatory response is not known. Although the role of LPS-exposed microglia in the AD brain is not clear, accumulating evidence suggests that LPS may exacerbate AD pathology through interactions with several receptors related to neuroinflammation $[158,159]$. Notably, LPS significantly increases the expression level of RAGE [160], a receptor critically involved in AD pathology such as $A \beta$ production and clearance, tau pathology, and synaptic degeneration [161]. In particular, the microglial RAGE-dependent signaling pathway plays a causative role in neuroinflammation, $\mathrm{A} \beta$ deposition, and cognitive impairment in $\mathrm{AD}$ 
[162]. Interestingly, it has been reported that stimulation of RAGE by LPS increases endothelial permeability and activates NF- $\mathrm{kB}$ [163]. The glial NF- $\mathrm{kB}$ activation by LPS leads to secretion of pro-inflammatory cytokines. In addition, recent studies have suggested that LPS can induce leukocyte infiltration into the brain and microglial activation by increasing the generation of reactive oxygen species through NADPH oxidase 2 (NOX2) activation [164]. The widespread high-level LPS in the AD brain alone can cause pathological and excessive neuroinflammatory reactions. Interestingly, LPS is also a ligand for triggering receptors expressed on myeloid cells 2 (TREM2), a receptor that regulates microglial phenotype switching [165]. Stimulation of TREM2 by LPS can convert the microglial phenotype from an anti-inflammatory phenotype to a pro-inflammatory phenotype [166]. Particularly, not only $A \beta$-induced neuroinflammation but also LPS-induced neuroinflammation could facilitate neurodegeneration and cognitive impairment [167]. These results suggest that the LPS-induced neuroinflammation could act as a direct and fatal factor in AD pathology and cognitive dysfunction.

\section{Neurodegeneration}

LPS induces synaptic loss within the CNS [168] and reduces synaptic plasticity in the brain [169]. Moreover, LPS affects the inhibitory and excitatory synapses of adult-born hippocampal neurons, induces neuronal and synaptic loss, and reduces cognitive function [170, 171], supporting the hypothesis that LPS in AD is involved in neurodegeneration (Fig. 4). In addition, LPS can inhibit neuronal function via damage to myelin in $\mathrm{AD}$ [172]. It has been reported that LPS causes damage to oligodendrocytes and increases myelin basic protein degradation in the AD brain. The first mechanism for LPS-induced neurodegeneration is that LPS induces the activated $\mathrm{p} 38 \alpha$ MAPK signaling pathway in microglia and increases TNF- $\alpha$ secretion $[173,174]$. In addition, LPS is one of the potent factors capable of activating NOX2 in the CNS $[164,175]$. The NOX2 activation in glia and neurons can induce neuronal cell death through massive oxidative stress, which has been suggested as a contributor to several neurodegenerative diseases, including AD $[176,177]$. The LPS-induced neuroinflammation such as NOX2 activation can be a possible additional contributor to neurodegeneration in AD pathology. Second, LPS facilitates neurodegeneration through mitochondrial dysfunction [178]; namely, LPS may affect mitochondrial fusion genes, such as mitofusin (Mfn)1, Mfn2, and OPA1, which are important in neurodegenerative diseases, including AD. In addition, LPS leads to neurodegeneration by inducing oxidative stress and triggering the mitochondrial apoptotic pathway [179]. Third, LPS can directly induce neuronal cell death through neuronal TLR4, which is a major receptor that plays a key role in the activation of the inflammatory response on AD. LPS not only increases TLR4 expression but also acts as a ligand for neuronal TLR4, inducing the transcription of caspase-11 and promoting the activation of the inflammasome $[180,181]$. Since TLR4 expression is also increased by aging and $A \beta$, the interaction between LPS and TLR4 may be more fatal to AD [182]. NF-kB, a well-known downstream molecule of the TLR4/Myd88/ TRIF signaling pathway, is also known to be important for neuronal survival and acts either as a pro-apoptotic or anti-apoptotic factor [183]. Consequently, LPS can cause neuronal death by directly acting on neurons, such as acting on neuronal receptors followed by influx into neuronal cells through OMV [181]. Taken together, these studies demonstrate that LPS can induce neurodegeneration and affect the initiation and progression of AD.

\section{Gram-negative bacteria and their LPS as therapeutic targets in AD}

The paradigm of $\mathrm{AD}$ treatment research is transforming from identifying a single target towards a multi-target therapy for various pathogenic factors. Interestingly, several therapeutic approaches targeting LPS-releasing gram-negative bacteria and microbiota have been proposed.

\section{Antibiotics for AD treatment}

Consistent with the influence of gram-negative bacteria on $\mathrm{AD}$ pathology, antibiotics have been demonstrated to reduce pathological changes in $\mathrm{AD}$ animal models and improve symptoms in AD patients (Table 5). Accumulating evidence on antibiotic therapy for AD suggests that the decrease of gram-negative bacteria involved in AD-related pathology by antibiotics is beneficial in the treatment of AD. However, some studies have suggested potential risk of side effects associated with their long-term use [184]. One of the largest risk factors is the antibiotic-induced microbiome imbalance [185]. In particular, a broad range of antibiotics can affect both gram-positive and gram-negative bacteria, resulting in imbalanced gut microbiota homeostasis [186]. This possibility should be fully considered in the development of $\mathrm{AD}$ antibiotic therapies. Unfortunately, there are no specific antibiotics for gram-negative bacteria in clinical trials for AD treatment. As the LPS from gram-negative bacteria has a remarkable adverse effect on AD, it would be important to develop a drug that not only targets gram-negative bacteria but also neutralizes the secreted/ remaining endotoxin. Consequently, to minimize the side 


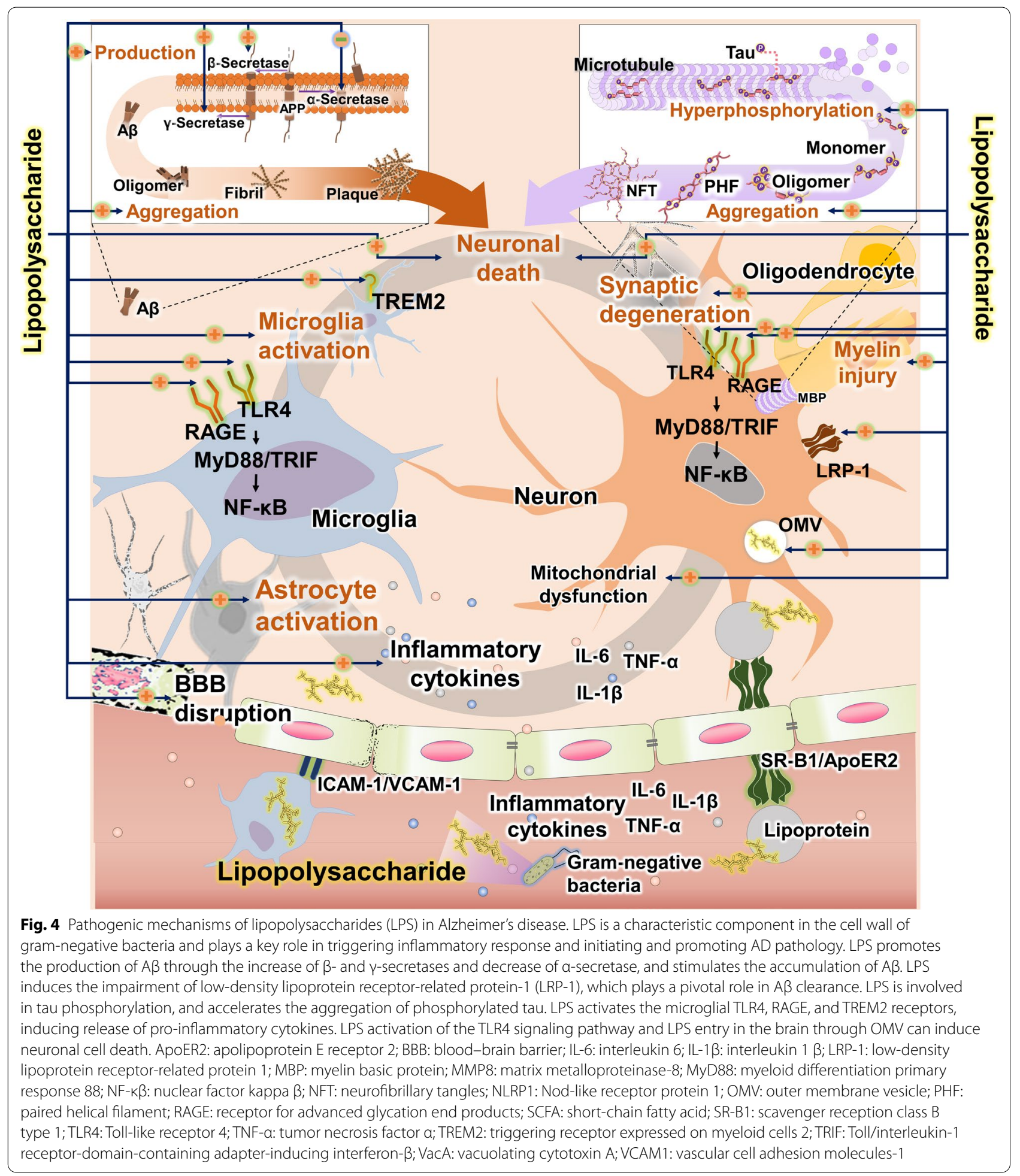

effects of existing broad-spectrum antibiotics, multispecific-target antibiotics, which target AD-specific gramnegative bacteria and their LPS, must be used.

\section{Gingipain inhibitor for AD treatment}

$P$. gingivalis is a typical gram-negative bacterium that exerts a broad and powerful effect on $\mathrm{AD}$ pathogenesis [104]. Gingipain, one of the byproducts of P. gingivalis, 
is a novel therapeutic target for AD treatment, which is associated with $A D$-related pathologies, such as $A \beta$ and tau pathology, neuroinflammation, and neurodegeneration (Table 3). Indeed, the use of selective inhibitors for gingipain can significantly reduce AD pathology [204]. For instance, COR388, a gingipain inhibitor, is currently under a phase 3 clinical trial (NCT03823404) (Table 5). Taken together, the bacterial exotoxin-specific drugs, such as gingipain inhibitors, can be an attractive therapeutic strategy, as they can simultaneously reduce and inhibit AD-related bacteria and bacterial exotoxin, respectively.

\section{Probiotics for AD treatment}

Probiotics have beneficial effects including immune system modulation, synthesis and release of neurotransmitters, protection from physiological stress, host gene expression modulation, pathogen antagonism, and improvement of intestinal epithelial barrier function [205]. Moreover, the hippocampal expression of $\mathrm{N}$-methyl-D-aspartic acid receptor, which is very important in AD pathology, is regulated by gut microbiota [206]. Several studies have suggested the potential therapeutic effect of probiotics in AD (Table 5). Surprisingly, many studies demonstrated that the probiotic treatment in rodent models of $\mathrm{AD}$ can reduce $\mathrm{A} \beta$ plaques and NFT [191, 192], alleviate neurodegeneration [190, 207], and restore the reduced acetylcholine level [192]. Furthermore, probiotics restore cognitive dysfunction in $\mathrm{AD}$ rodent models [190-192]. Evidence for the improvement of AD-related pathology by probiotics has been reported both in AD animal models and in patients. A clinical trial conducted in patients with $\mathrm{AD}$ has reported that a 12-week probiotic administration significantly improves the cognitive function in AD patients [193, 195]. The probiotic administration to $\mathrm{AD}$ patients has also been reported to alleviate systemic inflammation by reducing intestinal inflammation [194]. The effects of probiotics both in $\mathrm{AD}$ animal models and patients might occur through direct probiotic bacterial interaction with $\mathrm{AD}$ pathology and the correction of AD-induced microbial dysbiosis. Disruption of microbiota homeostasis, which is maintained through competition between bacterial species, could lead to pathological conditions. Attempts to rebuild the gut microbiota through dietary modulation and intake of food components are receiving attention in the treatment of AD. Modulating the microbiota bias is an important factor in the treatment of many diseases. Considering the changes in gram-negative bacteria in AD (Table 1), the mechanisms of action of probiotics on $\mathrm{AD}$ may also include a probiotic antagonistic action against the dysbiosis of gram-negative bacteria.

\section{Intestinal microbiota reconstruction for $A D$ treatment} Microbiota dysbiosis is an important factor in AD-related pathogenesis and progression [208], and several attempts have been made to improve microbiota dysbiosis and the alteration of gram-negative bacteria in AD (Table 5). First, attempts to induce the rebuilding of the gut microbiota through intake of the diet and food components are receiving attention for the treatment of AD [209]. For instance, a Mediterranean-style diet, which emphasizes plant-based foods such as vegetables, beans, whole grain, fruits, nuts and seeds, and plant-based oils [210], was reported to modulate the gut microbiota affecting AD pathology [197, 211]. One study demonstrated that the gut microbiota distribution alters in MCI patients on a Mediterranean diet, particularly decreasing the abundance of gram-negative bacteria Enterobacteriaceae, Akkermansia, Christensenllaceae, and Erysipelotriaceae [211]. Moreover, curcumin can improve AD pathology by regulating the proportion of gram-negative bacteria such as Bacteroidaceae, Rikenellaceae, and Prevotellaceae in AD transgenic mice [198]. Similarly, supplementation of omega-3 fatty acid and DHA alleviates microbiota dysbiosis and reduces AD-related gram-negative bacteria, such as Bacteroidetes, in healthy individuals [212, 213]. Vitamins are closely correlated with microbiota, and intake of folate and vitamin B-12 has been reported to be important for intestinal microbiota homeostasis in a rodent AD model [199, 209]. Moreover, traditional herbal medicine can induce changes in the microbiota in AD. The Ginsenoside Rg1, a traditional herbal medicine, can affect the microbiota of the large intestine by significantly reducing the abundance of gram-negative bacteria, $\mathrm{Bac}$ teroidetes, in the tree shrew model of AD [200]. Second, microbiota or fecal transplantation, which involves transplantation of microbiota in the feces of healthy humans into patients to balance the intestinal microflora, is an emerging therapeutic method for AD treatment [203]. Microbiota modulation both reduces cognitive impairment and $A \beta$ aggregates, and restores the impaired neuronal proteolytic pathways in 3xTg mice [214]. Moreover, recent studies have reported therapeutic effects of microbiota transplantation, including reduction of $A \beta$ deposition and NFT, alleviation of neuroinflammation, and amelioration of cognitive decline in $\mathrm{ADLP}^{\mathrm{APT}}$ mice [215]; and alleviation of behavioral and psychological symptoms of dementia and continuous improvement of cognitive function in elderly patients with $\mathrm{AD}$ who received fecal transplants [216]. However, the safety of fecal transplantation remains controversial. Recently, a patient who underwent fecal transplantation died from E. coli infection, a gram-negative bacterium that secrete "extendedspectrum beta-lactamase" [217]. This suggests that the transplantation of microbiota-including gram-negative 


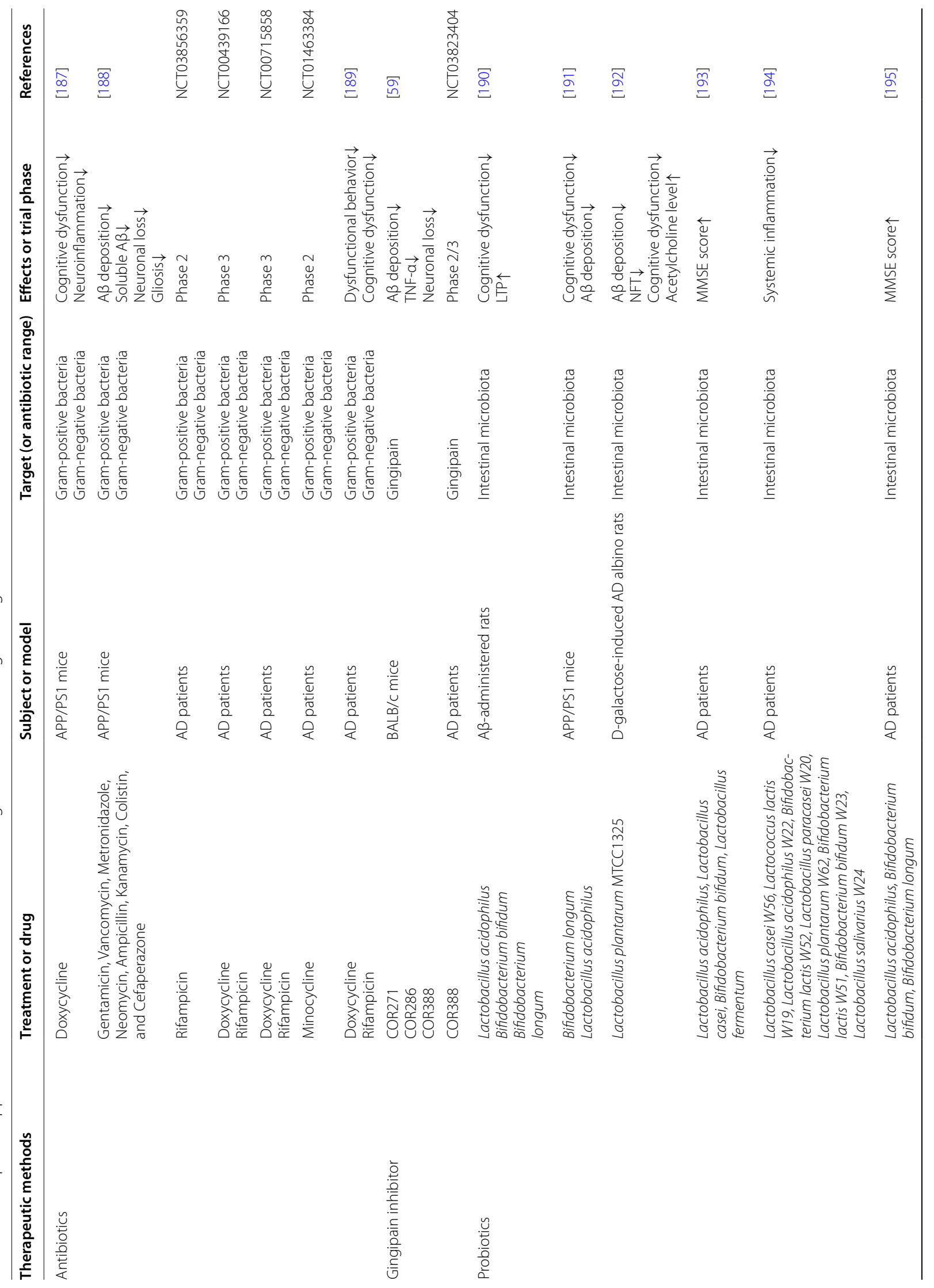




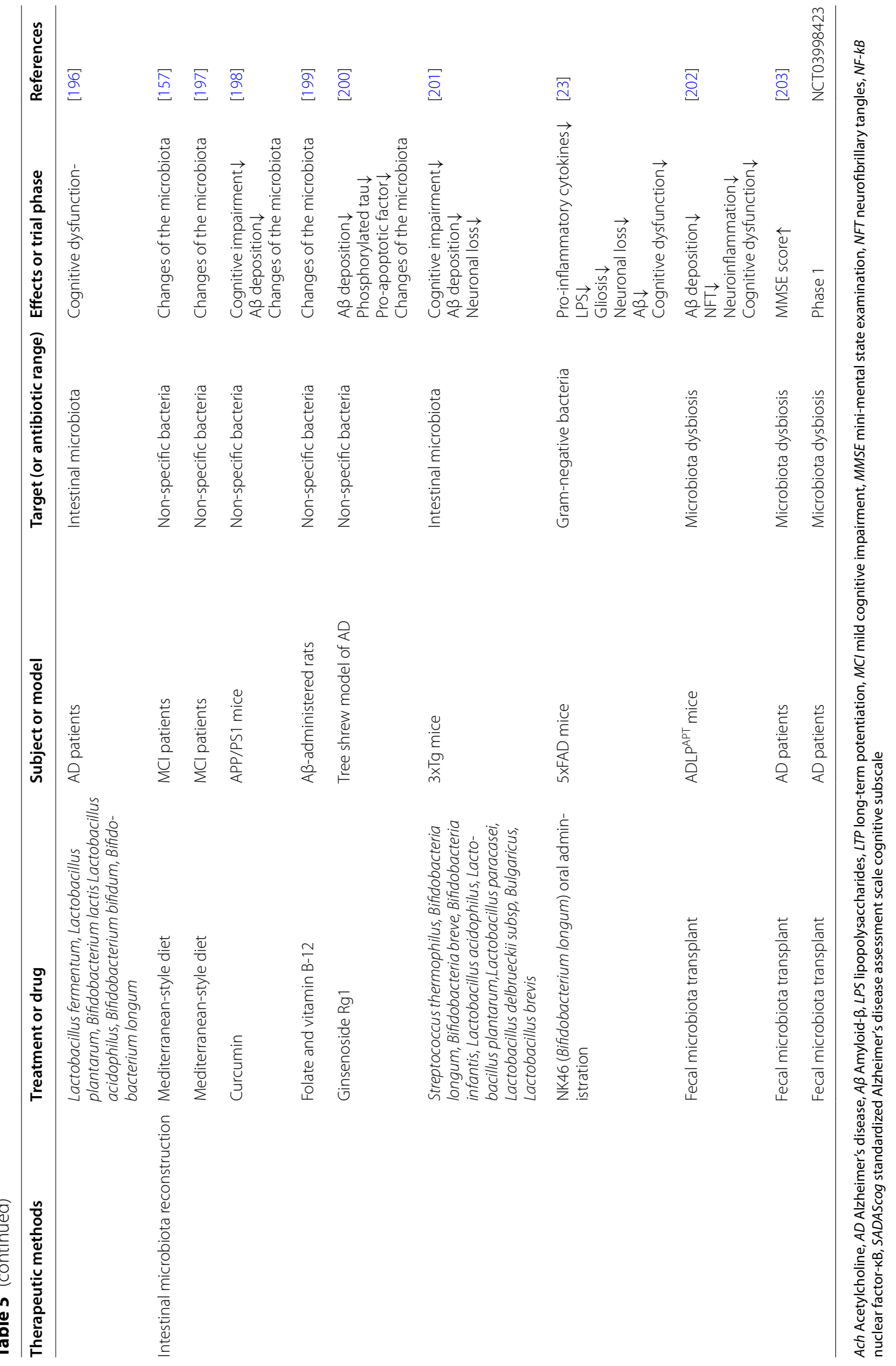


bacteria-is an unstable AD treatment. Despite the controversy on stability and side effects, the reconstruction of microbiota distribution through fecal transplantation has relieved the AD-related pathology in both animals and patients with $\mathrm{AD}$. These results suggest that the microbiota, including gram-negative bacteria, may not only be an upstream etiology of AD onset and progression, but also a therapeutic target for $\mathrm{AD}$ treatment.

\section{Conclusions}

The gram-negative bacteria and their LPS are detected in the CNS as well as in the periphery, and can trigger or accelerate $\mathrm{AD}$ pathology. We discuss the alterations and species of gram-negative bacteria in AD (Tables 1 and 2). The gram-negative bacteria can directly penetrate the CNS through various mechanisms (Fig. 1) and influence AD pathogenesis (Fig. 2). Moreover, several gramnegative bacteria are involved in microbiota dysbiosis, A $\beta$ pathology, tau hyperphosphorylation, neuroinflammation, and neurodegeneration in AD. Furthermore, the impact of gram-negative bacterial byproducts on major $\mathrm{AD}$ pathologies suggests that the gram-negative bacteria are an essential therapeutic target for AD (Table 3). Importantly, gram-negative bacteria-derived LPS, which is present at high concentrations in $\mathrm{AD}$ patients, is a direct pathogenic factor (Fig. 4). The AD pathologyrelated localization of LPS within the CNS suggests that LPS has unique pathological roles in AD (Table 4). Moreover, LPS is directly involved in AD pathology, including neuroinflammation through microglial TLR4 and induction of neuronal cell death through neuronal TLR4. The 'LPS cascade phenomenon', which acts as an upstream molecule triggering $\mathrm{AD}$ pathogenesis or accelerating progression by engagement in various aspects of AD pathology, should be considered as a potential therapeutic target for AD treatment. As a novel therapeutic strategy for $\mathrm{AD}$, the modulation of LPS-releasing gramnegative bacteria is receiving much attention (Table 5). Although the bacteria-targeting treatments, such as antibiotics and fecal microbiota transplantation, show potential for $\mathrm{AD}$ treatment, there are still concerns regarding their side effects and safety. In particular, potential side effects of the use of non-specific drugs that target bacteria indiscriminately should receive cautions. Therefore, it is important to categorize and characterize gram-negative bacteria that affect $\mathrm{AD}$. Taken together, the gramnegative bacteria and their LPS are not only an upstream pathologic process which influences $A \beta$ and tau pathology, but are also attractive targets for $\mathrm{AD}$ treatment. With no practical treatment for AD yet in development, the control of gram-negative bacteria and their LPS may be an excellent strategy to prevent the onset and progression of AD.

\section{Abbreviations}

AD: Alzheimer's disease; ADAM10: A disintegrin and metalloproteinase domain-containing protein 10; Akt: Protein kinase B; ApoE: Apolipotein E; apoER2: Apolipoprotein E receptor 2; APP/PS1: Amyloid precursor protein/ presenilin 1; A $\beta$ : Amyloid beta; BACE-1: Beta-site amyloid precursor protein cleaving enzyme 1; BBB: Blood-brain barrier; C. pneumoniae: Chlamydia pneumoniae; CD14: Cluster of differentiation 14; CDK-5: Cyclin-dependent kinase 5; CNS: Central nervous system; CSF: Cerebrospinal fluid; E. coli: Escherichia coli; Ecgp96: Endothelial receptors beta-form of the heat-shock gp96; GSk-33: Glycogen synthase kinase-3 $\beta$; H. pylori: Helicobacter pylori; IbeA: Invasion of the brain endothelium protein A; IL: Interleukin; iNOS: Inducible nitric oxide synthase; LBP: Lipopolysaccharide binding protein; LPS: Lipopolysaccharide; LRP-1: Lipoprotein receptor-related protein 1; MAPK: Mitogen-activated protein kinase; MG: Methylglyoxal; MyD88/TRIF: Myeloid differentiation primary response 88/toll/interleukin-1 receptor-domain-containing adapter-inducing interferon- $\beta$; NFT: Neurofibrillary tangles; NF-kB: Nuclear factor kappa-lightchain-enhancer of activated B; OmPA: Outer membrane protein A; OMV: Outer membrane vesicle; P. gingivalis: Porphyromonas gingivalis; PI3K: Phosphoinositide-3-kinase; RAGE: Receptor for advanced glycation end products; SCFA: Short-chain fatty acids; TLR: Toll-like receptor; TREM2: Triggering receptor expressed on myeloid cells 2; VacA: Vacuolating cytotoxin A.

\section{Supplementary Information}

The online version contains supplementary material available at https://doi. org/10.1186/s40035-021-00273-y.

Additional file 1: Figure S1. Flow diagram showing the study selection process. Flowchart summarizing study selection and inclusion processes in this narrative review, including the example of keywords that were reviewed.

\section{Acknowledgements}

Not applicable.

\section{Authors' contributions}

YN, S-MK, CWK and KWL and IDJ performed the literature search. HSK, SK, SJS and YHP created tables and figures. HSK, SK, SJS, YHP, MM, Y-MP and HDY contributed to the writing and editing of the manuscript. All authors read and approved this manuscript.

\section{Funding}

This research was funded by the Basic Science Research Program of the National Research Foundation of Korea (NRF), which is funded by the Ministry of Science, ICT \& Future Planning (NRF-2018R1D1A3B07041059 to M.M. and NRF-2016R1A5A2012284 to Y.-M.P.), by the Cooperative Research Program for Agriculture Science and Technology Development (Project No. PJ01428603), Rural Development Administration, Republic of Korea, and by the Korea Health Technology R\&D Project through the Korea Health Industry Development Institute (KHIDI), funded by the Ministry of Health \& Welfare, Republic of Korea (grant number: HF21C0021).

Availability of data and materials Not applicable.

\section{Declarations}

Ethics approval and consent to participate Not applicable.

Consent for publication Not applicable. 


\section{Competing interests}

Authors declare no competing interests.

\section{Author details}

${ }^{1}$ Department of Biochemistry, College of Medicine, Konyang University, Daejeon 35365, Republic of Korea. ${ }^{2}$ Research Institute for Dementia Science, Konyang University, Daejeon 35365, Republic of Korea. ${ }^{3}$ Dandi Bioscience Inc, 6th Floor of Real Company Building, 66, Achasan-ro, Sungdong-gu, Seoul, Republic of Korea. ${ }^{4}$ Harvard Neurology Clinic, 294 Gwanggyojungang-ro, Suji-gu, Yongin 16943, Republic of Korea. ${ }^{5}$ Department of Immunology, School of Medicine, Konkuk University, 268, Chungwondaero, Chungju-si, Chungcheongbuk-do, Republic of Korea.

\section{Received: 27 July 2021 Accepted: 9 November 2021}

Published online: 07 December 2021

\section{References}

1. 2020 Alzheimer's disease facts and figures. Alzheimers Dement 2020.

2. De-Paula VJ, Radanovic M, Diniz BS, Forlenza OV. Alzheimer's disease. Subcell Biochem. 2012:65:329-52.

3. Jack CR Jr, Bennett DA, Blennow K, Carrillo MC, Dunn B, Haeberlein SB, et al. NIA-AA research framework: toward a biological definition of Alzheimer's disease. Alzheimers Dement. 2018;14:535-62.

4. Mehta D, Jackson R, Paul G, Shi J, Sabbagh M. Why do trials for Alzheimer's disease drugs keep failing? A discontinued drug perspective for 2010-2015. Expert Opin Investig Drugs. 2017;26:735-9.

5. Mawanda F, Wallace R. Can infections cause Alzheimer's disease? Epidemiol Rev. 2013;35:161-80.

6. Abbott A. Are infections seeding some cases of Alzheimer's disease? Nature. 2020;587:22-5.

7. Sochocka M, Zwolinska K, Leszek J. The infectious etiology of Alzheimer's disease. Curr Neuropharmacol. 2017;15:996-1009.

8. Kim SH, Noh MY, Kim HJ, Oh KW, Park J, Lee S, et al. A therapeutic strategy for Alzheimer's disease focused on immune-inflammatory modulation. Dement Neurocogn Disord. 2019;18:33-46.

9. Vogt NM, Kerby RL, Dill-McFarland KA, Harding SJ, Merluzzi AP, Johnson SC, et al. Gut microbiome alterations in Alzheimer's disease. Sci Rep. 2017;7:13537.

10. Wang $X$, Sun G, Feng T, Zhang J, Huang $X$, Wang T, et al. Sodium oligomannate therapeutically remodels gut microbiota and suppresses gut bacterial amino acids-shaped neuroinflammation to inhibit Alzheimer's disease progression. Cell Res. 2019;29:787-803.

11. Pritchard AB, Crean S, Olsen I, Singhrao SK. Periodontitis, microbiomes and their role in Alzheimer's disease. Front Aging Neurosci. 2017:9:336.

12. Giau WV, Wu SY, Jamerlan A, An SSA, Kim SY, Hulme J. Gut microbiota and their neuroinflammatory implications in Alzheimer's disease. Nutrients. 2018;10:1765.

13. Emery DC, Shoemark DK, Batstone TE, Waterfall CM, Coghill JA, Cerajewska TL, et al. 16S rRNA next generation sequencing analysis shows bacteria in Alzheimer's post-mortem brain. Front Aging Neurosci. 2017:9:195.

14. Jiang C, Li G, Huang P, Liu Z, Zhao B. The gut microbiota and Alzheimer's disease. J Alzheimers Dis. 2017;58:1-15

15. Zhan X, Stamova B, Jin LW, DeCarli C, Phinney B, Sharp FR. Gram-negative bacterial molecules associate with Alzheimer disease pathology. Neurology. 2016;87:2324-32.

16. Pretorius E, Bester J, Kell DB. A bacterial component to Alzheimer'stype dementia seen via a systems biology approach that links iron dysregulation and inflammagen shedding to disease. J Alzheimers Dis. 2016;53:1237-56.

17. Fulop T, Witkowski JM, Bourgade K, Khalil A, Zerif E, Larbi A, et al. Can an infection hypothesis explain the beta amyloid hypothesis of Alzheimer's disease? Front Aging Neurosci. 2018;10:224.

18. Brown GC. The endotoxin hypothesis of neurodegeneration. J Neuroinflammation. 2019;16:180.

19. Hung YL, Fang SH, Wang SC, Cheng WC, Liu PL, Su CC, et al. Corylin protects LPS-induced sepsis and attenuates LPS-induced inflammatory response. Sci Rep. 2017;7:46299.
20. Chou CH, Lee JT, Lin CC, Sung YF, Lin CC, Muo CH, et al. Septicemia is associated with increased risk for dementia: a population-based longitudinal study. Oncotarget. 2017:8:84300-8.

21. Iwashyna TJ, Ely EW, Smith DM, Langa KM. Long-term cognitive impairment and functional disability among survivors of severe sepsis. JAMA. 2010;304:1787-94.

22. Zhang R, Miller RG, Gascon R, Champion S, Katz J, Lancero M, et al. Circulating endotoxin and systemic immune activation in sporadic amyotrophic lateral sclerosis (sALS). J Neuroimmunol. 2009:206:121-4.

23. Lee HJ, Lee KE, Kim JK, Kim DH. Suppression of gut dysbiosis by Bifidobacterium longum alleviates cognitive decline in 5XFAD transgenic and aged mice. Sci Rep. 2019;9:11814.

24. Zhan X, Stamova B, Sharp FR. Lipopolysaccharide associates with amyloid plaques, neurons and oligodendrocytes in Alzheimer's disease brain: a review. Front Aging Neurosci. 2018;10:42

25. Honjo K, van Reekum R, Verhoeff NP. Alzheimer's disease and infection: do infectious agents contribute to progression of Alzheimer's disease? Alzheimers Dement. 2009:5:348-60.

26. Beydoun MA, Beydoun HA, Weiss J, Hossain S, El-Hajj ZW, Zonderman AB. Helicobacter pylori, periodontal pathogens, and their interactive association with incident all-cause and Alzheimer's disease dementia in a large national survey. Mol Psychiatry 2020

27. Beydoun MA, Beydoun HA, Hossain S, El-Hajj ZW, Weiss J, Zonderman $A B$. Clinical and bacterial markers of periodontitis and their association with incident all-cause and Alzheimer's disease dementia in a large national survey. J Alzheimers Dis. 2020;75:157-72.

28. Park J, Kim TJ, Song JH, Jang H, Kim JS, Kang SH, et al. Helicobacter pylori infection is associated with neurodegeneration in cognitively normal men. J Alzheimers Dis. 2021;82:1591-9.

29. Zilli EM, O'Donnell A, Salinas J, Aparicio HJ, Gonzales MM, Jacob M, Beiser A, et al. Herpes Labialis, Chlamydophila pneumoniae, Helicobacter pylori, and cytomegalovirus infections and risk of dementia: the framingham heart study. J Alzheimers Dis. 2021;82:593-605.

30. Fu P, Gao M, Yung KKL. Association of intestinal disorders with Parkinson's disease and Alzheimer's disease: a systematic review and metaanalysis. ACS Chem Neurosci. 2020;11:395-405.

31. Beydoun MA, Beydoun HA, Elbejjani M, Dore GA, Zonderman AB. Helicobacter pylori seropositivity and its association with incident all-cause and Alzheimer's disease dementia in large national surveys. Alzheimers Dement. 2018;14:1148-58.

32. Harach T, Marungruang N, Duthilleul N, Cheatham V, Mc Coy KD, Frisoni $\mathrm{G}$, et al. Reduction of Abeta amyloid pathology in APPPS1 transgenic mice in the absence of gut microbiota. Sci Rep. 2017;7:41802.

33. Shen L, Liu L, Ji HF. Alzheimer's disease histological and behavioral manifestations in transgenic mice correlate with specific gut microbiome state. J Alzheimers Dis. 2017:56:385-90.

34. Bauerl C, Collado MC, Diaz Cuevas A, Vina J, Perez Martinez G. Shifts in gut microbiota composition in an APP/PSS1 transgenic mouse model of Alzheimer's disease during lifespan. Lett Appl Microbiol. 2018;66:464-71.

35. Brandscheid C, Schuck F, Reinhardt S, Schafer KH, Pietrzik CU, Grimm M, et al. Altered gut microbiome composition and tryptic activity of the 5xFAD Alzheimer's mouse model. J Alzheimers Dis. 2017:56:775-88.

36. Maclntyre A, Abramov R, Hammond CJ, Hudson AP, Arking EJ, Little CS, et al. Chlamydia pneumoniae infection promotes the transmigration of monocytes through human brain endothelial cells. J Neurosci Res. 2003;71:740-50.

37. Arking EJ, Appelt DM, Abrams JT, Kolbe S, Hudson AP, Balin BJ. Ultrastructural analysis of Chlamydia pneumoniae in the Alzheimer's brain. Pathogenesis (Amst). 1999;1:201-11.

38. Poole S, Singhrao SK, Kesavalu L, Curtis MA, Crean S. Determining the presence of periodontopathic virulence factors in short-term postmortem Alzheimer's disease brain tissue. J Alzheimers Dis. 2013;36:665-77.

39. Huma Siddiqui ERE, Singhrao SK, Olsen I. High throughput sequencing detect gingivitis and periodontal oral bacteria in Alzheimer's disease autopsy brains. Neuro Res. 2019:1:3.

40. Balin BJ, Gerard HC, Arking EJ, Appelt DM, Branigan PJ, Abrams JT, Whittum-Hudson JA, Hudson AP. Identification and localization of Chlamydia pneumoniae in the Alzheimer's brain. Med Microbiol Immunol. 1998;187:23-42. 
41. Gerard HC, Dreses-Werringloer U, Wildt KS, Deka S, Oszust C, Balin BJ, et al. Chlamydophila (Chlamydia) pneumoniae in the Alzheimer's brain. FEMS Immunol Med Microbiol. 2006;48:355-66.

42. Riviere GR, Riviere KH, Smith KS. Molecular and immunological evidence of oral Treponema in the human brain and their association with Alzheimer's disease. Oral Microbiol Immunol. 2002;17:113-8.

43. Gerard HC, Wildt KL, Whittum-Hudson JA, Lai Z, Ager J, Hudson AP. The load of Chlamydia pneumoniae in the Alzheimer's brain varies with APOE genotype. Microb Pathog. 2005;39:19-26.

44. Miklossy J, Kasas S, Janzer RC, Ardizzoni F, Van der Loos H. Further ultrastructural evidence that spirochaetes may play a role in the aetiology of Alzheimer's disease. NeuroReport. 1994;5:1201-4.

45. Dreses-Werringloer U, Bhuiyan M, Zhao Y, Gerard HC, Whittum-Hudson JA, Hudson AP. Initial characterization of Chlamydophila (Chlamydia) pneumoniae cultured from the late-onset Alzheimer brain. Int J Med Microbiol. 2009;299:187-201.

46. Miklossy J, Khalili K, Gern L, Ericson RL, Darekar P, Bolle L, et al. Borrelia burgdorferi persists in the brain in chronic lyme neuroborreliosis and may be associated with Alzheimer disease. J Alzheimers Dis. 2004:6:639-49.

47. Paradowski B, Jaremko M, Dobosz T, Leszek J, Noga L. Evaluation of CSF-Chlamydia pneumoniae, CSF-tau, and CSF-Abeta42 in Alzheimer's disease and vascular dementia. J Neurol. 2007:254:154-9.

48. Kountouras J, Boziki M, Gavalas E, Zavos C, Deretzi G, Grigoriadis N, et al. Increased cerebrospinal fluid Helicobacter pylori antibody in Alzheimer's disease. Int J Neurosci. 2009;119:765-77.

49. Miklossy J. Alzheimer's disease-a spirochetosis? NeuroReport. 1993:4:841-8

50. Zhang L, Wang Y, Xiayu X, Shi C, Chen W, Song N, et al. Altered gut microbiota in a mouse model of Alzheimer's disease. J Alzheimers Dis. 2017:60:1241-57.

51. Chen C, Ahn EH, Kang SS, Liu X, Alam A, Ye K. Gut dysbiosis contributes to amyloid pathology, associated with C/EBPbeta/AEP signaling activation in Alzheimer's disease mouse model. Sci Adv. 2020;6:eaba0466.

52. Bu XL, Yao XQ, Jiao SS, Zeng F, Liu YH, Xiang Y, et al. A study on the association between infectious burden and Alzheimer's disease. Eur J Neurol. 2015;22:1519-25.

53. Herrera-Landero A, Amaya-Sánchez LE, De Las-Deses CD, SolórzanoSantos F, Gordillo-Pérez MG. Borrelia burgdorferi as a risk factor for Alzheimer's dementia and mild cognitive impairment. Eur Geriatr Med. 2019;10:493-500.

54. Al-Obaidi MMJ, Desa MNM. Mechanisms of blood brain barrier disruption by different types of bacteria, and bacterial-host interactions facilitate the bacterial pathogen invading the brain. Cell Mol Neurobiol. 2018;38:1349-68.

55. Zhou Y, Tao J, Yu H, Ni J, Zeng L, Teng Q, et al. Hcp family proteins secreted via the type VI secretion system coordinately regulate Escherichia coli K1 interaction with human brain microvascular endothelial cells. Infect Immun. 2012;80:1243-51.

56. Mittal R, Prasadarao NV. Nitric oxide/cGMP signalling induces Escherichia coli K1 receptor expression and modulates the permeability in human brain endothelial cell monolayers during invasion. Cell Microbiol. 2010:12:67-83.

57. Kristensson K. Microbes' roadmap to neurons. Nat Rev Neurosci. 2011;12:345-57.

58. Rodriguez Coyago ML, Sanchez Temino VE. Periodontitis determining the onset and progression of Huntington's disease: review of the literature. Medwave. 2015;15:e6293.

59. Dominy SS, Lynch C, Ermini F, Benedyk M, Marczyk A, Konradi A, et al. Porphyromonas gingivalis in Alzheimer's disease brains: evidence for disease causation and treatment with small-molecule inhibitors. Sci Adv. 2019;5:eaau3333

60. Poole S, Singhrao SK, Chukkapalli S, Rivera M, Velsko I, Kesavalu L, et al. Active invasion of Porphyromonas gingivalis and infection-induced complement activation in ApoE-/- mice brains. J Alzheimers Dis. 2015:43:67-80.

61. Doulberis M, Kotronis G, Thomann R, Polyzos SA, Boziki M, Gialamprinou $D$, et al. Review: impact of Helicobacter pylori on Alzheimer's disease: what do we know so far? Helicobacter. 2018:23:12454.

62. Strandwitz P. Neurotransmitter modulation by the gut microbiota. Brain Res. 2018;1693:128-33.
63. Carabotti M, Scirocco A, Maselli MA, Severi C. The gut-brain axis: interactions between enteric microbiota, central and enteric nervous systems. Ann Gastroenterol. 2015:28:203-9.

64. Ma Q, Xing C, Long W, Wang HY, Liu Q, Wang RF. Impact of microbiota on central nervous system and neurological diseases: the gut-brain axis. J Neuroinflammation. 2019;16:53.

65. Liu S, Gao J, Zhu M, Liu K, Zhang HL. Gut microbiota and dysbiosis in Alzheimer's disease: implications for pathogenesis and treatment. Mol Neurobiol. 2020:57:5026-43.

66. Hill JM, Clement C, Pogue Al, Bhattacharjee S, Zhao Y, Lukiw WJ. Pathogenic microbes, the microbiome, and Alzheimer's disease (AD). Front Aging Neurosci. 2014;6:127.

67. Honarpisheh P, Reynolds CR, Blasco Conesa MP, Moruno Manchon JF, Putluri N, Bhattacharjee MB, et al. Dysregulated gut homeostasis observed prior to the accumulation of the brain amyloid-beta in Tg2576 mice. Int J Mol Sci. 2020;21:1711.

68. Schwartz K, Boles BR. Microbial amyloids-functions and interactions within the host. Curr Opin Microbiol. 2013;16:93-9.

69. Javed I, Zhang Z, Adamcik J, Andrikopoulos N, Li Y, Otzen DE, et al. Accelerated amyloid beta pathogenesis by bacterial amyloid FapC. Adv Sci. 2020;7:2001299.

70. Shewmaker F, McGlinchey RP, Thurber KR, McPhie P, Dyda F, Tycko R, et al. The functional curli amyloid is not based on in-register parallel beta-sheet structure. J Biol Chem. 2009;284:25065-76.

71. Hill JM, Lukiw WJ. Microbial-generated amyloids and Alzheimer's disease (AD). Front Aging Neurosci. 2015;7:9.

72. Chapman MR, Robinson LS, Pinkner JS, Roth R, Heuser J, Hammar M, et al. Role of Escherichia coli curli operons in directing amyloid fiber formation. Science. 2002;295:851-5.

73. Zhao Y, Dua P, Lukiw WJ. Microbial sources of amyloid and relevance to amyloidogenesis and Alzheimer's disease (AD). J Alzheimers Dis Parkinsonism. 2015;5:177.

74. Friedland RP, Chapman MR. The role of microbial amyloid in neurodegeneration. PLOS Pathog. 2017;13:e1006654.

75. Oskarsson ME, Paulsson JF, Schultz SW, Ingelsson M, Westermark P, Westermark GT. In vivo seeding and cross-seeding of localized amyloidosis: a molecular link between type 2 diabetes and Alzheimer disease. Am J Pathol. 2015;185:834-46.

76. Moreno-Gonzalez I, Edwards lii G, Salvadores N, Shahnawaz M, DiazEspinoza R, Soto C. Molecular interaction between type 2 diabetes and Alzheimer's disease through cross-seeding of protein misfolding. Mol Psychiatry. 2017;22:1327-34

77. Cherny I, Rockah L, Levy-Nissenbaum O, Gophna U, Ron EZ, Gazit E. The formation of Escherichia coli curli amyloid fibrils is mediated by prionlike peptide repeats. J Mol Biol. 2005;352:245-52.

78. Yan Z, Yin M, Chen J, Li X. Assembly and substrate recognition of curli biogenesis system. Nat Commun. 2020;11:241.

79. Van Gerven N, Klein RD, Hultgren SJ, Remaut H. Bacterial amyloid formation: structural insights into curli biogensis. Trends Microbiol. 2015;23:693-706.

80. Shu Q, Crick SL, Pinkner JS, Ford B, Hultgren SJ, Frieden C. The E. coli CsgB nucleator of curli assembles to beta-sheet oligomers that alter the CsgA fibrillization mechanism. Proc Natl Acad Sci USA. 2012;109:6502-7.

81. Dueholm MS, Petersen SV, Sonderkaer M, Larsen P, Christiansen G, Hein KL, et al. Functional amyloid in pseudomonas. Mol Microbiol. 2010;77:1009-20.

82. Javed I, Zhang Z, Adamcik J, Andrikopoulos N, Li Y, Otzen DE, et al. Accelerated amyloid beta pathogenesis by bacterial amyloid FapC. Adv Sci (Weinh). 2020;7:2001299.

83. Rapsinski GJ, Newman TN, Oppong GO, van Putten JP, Tukel C. CD14 protein acts as an adaptor molecule for the immune recognition of Salmonella curli fibers. J Biol Chem. 2013;288:14178-88.

84. Shin MG, Lee JW, Han JS, Lee B, Jeong JH, Park SH, et al. Bacteria-derived metabolite, methylglyoxal, modulates the longevity of $C$. elegans through TORC2/SGK-1/DAF-16 signaling. Proc Natl Acad Sci U S A. 2020;117:17142-50

85. Krautwald M, Munch G. Advanced glycation end products as biomarkers and gerontotoxins: a basis to explore methylglyoxal-lowering agents for Alzheimer's disease? Exp Gerontol. 2010;45:744-51. 
86. Cho HJ, Son SM, Jin SM, Hong HS, Shin DH, Kim SJ, et al. RAGE regulates BACE1 and Abeta generation via NFAT1 activation in Alzheimer's disease animal model. FASEB J. 2009;23:2639-49.

87. Ilievski V, Zuchowska PK, Green SJ, Toth PT, Ragozzino ME, Le K, et al. Chronic oral application of a periodontal pathogen results in brain inflammation, neurodegeneration and amyloid beta production in wild type mice. PLoS One. 2018;13:e0204941.

88. Armbrust F, Colmorgen C, Pietrzik CU, Becker-Pauly C. The Alzheimer's disease associated bacterial protease RgpB from $P$. gingivalis activates the alternative $\beta$-secretase meprin $\beta$ thereby increasing $A \beta$ generation. bioRxiv 2019;748814. https://doi.org/10.1101/748814

89. Li XH, Xie JZ, Jiang X, Lv BL, Cheng XS, Du LL, et al. Methylglyoxal induces tau hyperphosphorylation via promoting AGEs formation. Neuromol Med. 2012;14:338-48.

90. Cadamuro AC, Rossi AF, Maniezzo NM, Silva AE. Helicobacter pylori infection: host immune response, implications on gene expression and microRNAs. World J Gastroenterol. 2014;20:1424-37.

91. de Bernard M, Moschioni M, Papini E, Telford J, Rappuoli R, Montecucco C. Cell vacuolization induced by Helicobacter pylori VacA toxin: cell line sensitivity and quantitative estimation. Toxicol Lett. 1998;99:109-15.

92. Kumar H, Jo MJ, Choi H, Muttigi MS, Shon S, Kim BJ, et al. Matrix metalloproteinase-8 inhibition prevents disruption of blood-spinal cord barrier and attenuates inflammation in rat model of spinal cord injury. Mol Neurobiol. 2018;55:2577-90.

93. Blank M, Bashi T, Lachnish J, Ben-Ami-Shor D, Shovman O, Fridkin M, et al. Helminths-based bi-functional molecule, tuftsin-phosphorylcholine (TPC), ameliorates an established murine arthritis. PLoS One. 2018;13:e0200615.

94. Erny D, de Angelis ALH, Jaitin D, Wieghofer P, Staszewski O, David E, et al. Host microbiota constantly control maturation and function of microglia in the CNS. Nat Neurosci. 2015;18:965-77.

95. Colombo AV, Sadler RK, Llovera G, Singh V, Roth S, Heindl S, et al. Microbiota-derived short chain fatty acids modulate microglia and promote A $\beta$ plaque deposition. eLife. 2021;10:e59826. https://doi.org/ 10.7554/eLife.59826.

96. Marizzoni M, Cattaneo A, Mirabelli P, Festari C, Lopizzo N, Nicolosi $\checkmark$, et al. Short-chain fatty acids and lipopolysaccharide as mediators between gut dysbiosis and amyloid pathology in Alzheimer's disease. J Alzheimers Dis. 2020;78(2):683-97. https://doi.org/10.3233/JAD-200306.

97. Rothhammer V, Mascanfroni ID, Bunse L, Takenaka MC, Kenison JE, Mayo L, et al. Type I interferons and microbial metabolites of tryptophan modulate astrocyte activity and central nervous system inflammation via the aryl hydrocarbon receptor. Nat Med. 2016;22:586-97.

98. Iqbal K, Liu F, Gong CX, Grundke-Iqbal I. Tau in Alzheimer disease and related tauopathies. Curr Alzheimer Res. 2010;7:656-64.

99. Grundke-labal I, labal K, Quinlan M, Tung YC, Zaidi MS, Wisniewski HM. Microtubule-associated protein tau. A component of Alzheimer paired helical filaments. J Biol Chem. 1986;261:6084-9.

100. Khlistunova I, Biernat J, Wang Y, Pickhardt M, von Bergen M, Gazova $Z$, et al. Inducible expression of Tau repeat domain in cell models of tauopathy: aggregation is toxic to cells but can be reversed by inhibitor drugs. J Biol Chem. 2006;281:1205-14.

101. Ferrer I, Gomez-Isla T, Puig B, Freixes M, Ribe E, Dalfo E, et al. Current advances on different kinases involved in tau phosphorylation, and implications in Alzheimer's disease and tauopathies. Curr Alzheimer Res. 2005;2:3-18.

102. Wang $X L$, Zeng J, Yang $Y$, Xiong $Y$, Zhang ZH, Qiu M, et al. Helicobacter pylori filtrate induces Alzheimer-like tau hyperphosphorylation by activating glycogen synthase kinase-3beta. J Alzheimers Dis. 2015:43:153-65.

103. Haditsch U, Roth T, Rodriguez L, Hancock S, Cecere T, Nguyen M, et al. Alzheimer's disease-like neurodegeneration in Porphyromonas gingivalis infected neurons with persistent expression of active gingipains. J Alzheimers Dis. 2020;75:1361-76.

104. Kanagasingam S, Chukkapalli SS, Welbury R, Singhrao SK. Porphyromonas gingivalis is a strong risk factor for Alzheimer's disease. J Alzheimers Dis Rep. 2020;4:501-11.

105. Chu J, Lauretti E, Pratico D. Caspase-3-dependent cleavage of Akt modulates tau phosphorylation via GSK3beta kinase: implications for Alzheimer's disease. Mol Psychiatry. 2017;22:1002-8.
106. Kovacech B, Novak M. Tau truncation is a productive posttranslational modification of neurofibrillary degeneration in Alzheimer's disease. Curr Alzheimer Res. 2010:7:708-16.

107. Yin $\mathrm{H}$, Kuret J. C-terminal truncation modulates both nucleation and extension phases of tau fibrillization. FEBS Lett. 2006;580:211-5.

108. Taniguchi-Watanabe S, Arai T, Kametani F, Nonaka T, Masuda-Suzukake M, Tarutani A, et al. Biochemical classification of tauopathies by immunoblot, protein sequence and mass spectrometric analyses of sarkosylinsoluble and trypsin-resistant tau. Acta Neuropathol. 2016:131:267-80.

109. Tetz G, Pinho M, Pritzkow S, Mendez N, Soto C, Tetz V. Bacterial DNA promotes Tau aggregation. Sci Rep. 2020;10:2369.

110. Regen F, Hellmann-Regen J, Costantini E, Reale M. Neuroinflammation and Alzheimer's disease: implications for microglial activation. Curr Alzheimer Res. 2017;14:1140-8.

111. Kinney JW, Bemiller SM, Murtishaw AS, Leisgang AM, Salazar AM, Lamb BT. Inflammation as a central mechanism in Alzheimer's disease. Alzheimers Dement (N Y). 2018:4:575-90.

112. Dickson K, Lehmann C. Inflammatory response to different toxins in experimental sepsis models. Int J Mol Sci. 2019;20:4341.

113. McManus RM, Higgins SC, Mills KH, Lynch MA. Respiratory infection promotes $T$ cell infiltration and amyloid-beta deposition in APP/PS1 mice. Neurobiol Aging. 2014;35:109-21.

114. Balin BJ, Hammond CJ, Little CS, Hingley ST, Al-Atrache Z, Appelt DM, et al. Chlamydia pneumoniae: an etiologic agent for late-onset dementia. Front Aging Neurosci. 2018;10:302.

115. Ikejima H, Friedman $\mathrm{H}$, Yamamoto Y. Chlamydia pneumoniae infection of microglial cells in vitro: a model of microbial infection for neurological disease. J Med Microbiol. 2006;55:947-52.

116. Tajes M, Eraso-Pichot A, Rubio-Moscardo F, Guivernau B, RamosFernandez E, Bosch-Morato M, et al. Methylglyoxal produced by amyloid-beta peptide-induced nitrotyrosination of triosephosphate isomerase triggers neuronal death in Alzheimer's disease. J Alzheimers Dis. 2014;41:273-88.

117. Tajes M, Eraso-Pichot A, Rubio-Moscardo F, Guivernau B, Bosch-Morato $M$, Valls-Comamala V, et al. Methylglyoxal reduces mitochondrial potential and activates Bax and caspase-3 in neurons: implications for Alzheimer's disease. Neurosci Lett. 2014;580:78-82.

118. Calvo-Rodriguez M, Garcia-Rodriguez C, Villalobos C, Nunez L. Role of toll like receptor 4 in Alzheimer's disease. Front Immunol. 2020;11:1588.

119. Li Y, Zhang L, Tang J, Yang X, Huang J, Zhu T, et al. Role of toll-like receptor 4 in the regulation of the cell death pathway and neuroinflammation. Brain Res Bull. 2019;148:79-90.

120. d'Hennezel E, Abubucker S, Murphy LO, Cullen TW. Total lipopolysaccharide from the human gut microbiome silences Toll-like receptor signaling. Msystems. 2017;2:e00046-17.

121. Guo S, Al-Sadi R, Said HM, Ma TY. Lipopolysaccharide causes an increase in intestinal tight junction permeability in vitro and in vivo by inducing enterocyte membrane expression and localization of TLR-4 and CD14. Am J Pathol. 2013;182:375-87.

122. Ghosh SS, Wang J, Yannie PJ, Ghosh S. Intestinal barrier dysfunction, LPS translocation, and disease development. J Endocr Soc. 2020:4:bvz039.

123. Zhao Y, Jaber V, Lukiw WJ. Secretory products of the human GI tract microbiome and their potential impact on Alzheimer's disease (AD): detection of lipopolysaccharide (LPS) in AD hippocampus. Front Cell Infect Microbiol. 2017;7:318.

124. Zhao Y, Cong L, Lukiw WJ. Lipopolysaccharide (LPS) accumulates in neocortical neurons of Alzheimer's disease (AD) brain and impairs transcription in human neuronal-glial primary co-cultures. Front Aging Neurosci. 2017;9:407.

125. Zhao Y, Cong L, Jaber V, Lukiw WJ. Microbiome-derived lipopolysaccharide enriched in the perinuclear region of Alzheimer's disease brain. Front Immunol. 2017;8:1064.

126. Vargas-Caraveo A, Sayd A, Maus SR, Caso JR, Madrigal JLM, GarciaBueno $B$, et al. Lipopolysaccharide enters the rat brain by a lipoproteinmediated transport mechanism in physiological conditions. Sci Rep. 2017:7:13113.

127. Gotsch $U$, Jager $U$, Dominis M, Vestweber D. Expression of P-selectin on endothelial cells is upregulated by LPS and TNF-alpha in vivo. Cell Adhes Commun. 1994;2:7-14. 
128. Meena M, Cools N. On the road to new treatments for multiple sclerosis: targeting dendritic cell migration into the central nervous system. Neural Regen Res. 2019;14:2088-90.

129. Coisne C, Dehouck L, Faveeuw C, Delplace Y, Miller F, Landry C, et al. Mouse syngenic in vitro blood-brain barrier model: a new tool to examine inflammatory events in cerebral endothelium. Lab Invest. 2005;85:734-46.

130. Varatharaj A, Galea I. The blood-brain barrier in systemic inflammation. Brain Behav Immun. 2017:60:1-12.

131. Nonaka N, Shioda S, Banks WA. Effect of lipopolysaccharide on the transport of pituitary adenylate cyclase activating polypeptide across the blood-brain barrier. Exp Neurol. 2005;191:137-44.

132. WoodcockTE, Woodcock TM. Revised Starling equation and the glycocalyx model of transvascular fluid exchange: an improved paradigm for prescribing intravenous fluid therapy. Br J Anaesth. 2012;108:384-94.

133. Heinbockel L, Weindl G, Martinez-de-Tejada G, Correa W, SanchezGomez S, Barcena-Varela S, et al. Inhibition of lipopolysaccharide- and lipoprotein-induced inflammation by antitoxin peptide pep19-2.5. Front Immunol. 2018;9:1704.

134. Le Guennec L, Coureuil M, Nassif X, Bourdoulous S. Strategies used by bacterial pathogens to cross the blood-brain barrier. Cell Microbiol. 2020;22:e13132.

135. Pfalzgraff A, Correa W, Heinbockel L, Schromm AB, Lubow C, Gisch $\mathrm{N}$, et al. LPS-neutralizing peptides reduce outer membrane vesicleinduced inflammatory responses. Biochim Biophys Acta Mol Cell Biol Lipids. 2019;1864:1503-13.

136. Lee HJ, Hwang YH, Kim DH. Lactobacillus plantarum C29-fermented soybean (DW2009) alleviates memory impairment in 5XFAD transgenic mice by regulating microglia activation and gut microbiota composition. Mol Nutr Food Res. 2018;62:e1800359.

137. Kirk RA, Kesner RP, Wang LM, Wu Q, Towner RA, Hoffman JM, et al. Lipopolysaccharide exposure in a rat sepsis model results in hippocampal amyloid-beta plaque and phosphorylated tau deposition and corresponding behavioral deficits. Geroscience. 2019;41:467-81.

138. Lee JW, Lee YK, Yuk DY, Choi DY, Ban SB, Oh KW, et al. Neuro-inflammation induced by lipopolysaccharide causes cognitive impairment through enhancement of beta-amyloid generation. J Neuroinflammation. 2008:5:37.

139. Wu Z, Ni J, Liu Y, Teeling JL, Takayama F, Collcutt A, et al. Cathepsin B plays a critical role in inducing Alzheimer's disease-like phenotypes following chronic systemic exposure to lipopolysaccharide from Porphyromonas gingivalis in mice. Brain Behav Immun. 2017;65:350-61.

140. Deng X, Li M, Ai W, He L, Lu D, Patrylo PR, et al. Lipolysaccharideinduced neuroinflammation is associated with alzheimer-like amyloidogenic axonal pathology and dendritic degeneration in rats. Adv Alzheimer Dis. 2014;3:78-93.

141. Wang LM, Wu Q, Kirk RA, Horn KP, Ebada Salem AH, Hoffman JM, et al. Lipopolysaccharide endotoxemia induces amyloid-beta and p-tau formation in the rat brain. Am J Nucl Med Mol Imaging. 2018;8:86-99.

142. Erickson MA, Hartvigson PE, Morofuji Y, Owen JB, Butterfield DA, Banks WA. Lipopolysaccharide impairs amyloid beta efflux from brain: altered vascular sequestration, cerebrospinal fluid reabsorption, peripheral clearance and transporter function at the blood-brain barrier. J Neuroinflammation. 2012;9:150.

143. Sy M, Kitazawa M, Medeiros R, Whitman L, Cheng D, Lane TE, et al. Inflammation induced by infection potentiates tau pathological features in transgenic mice. Am J Pathol. 2011;178:2811-22.

144. Kitazawa M, Oddo S, Yamasaki TR, Green KN, LaFerla FM. Lipopolysaccharide-induced inflammation exacerbates tau pathology by a cyclin-dependent kinase 5-mediated pathway in a transgenic model of Alzheimer's disease. J Neurosci. 2005;25:8843-53.

145. Bahar B, Singhrao SK. An evaluation of the molecular mode of action of trans-resveratrol in the Porphyromonas gingivalis lipopolysaccharide challenged neuronal cell model. Mol Biol Rep. 2021;48:147-56.

146. Liu J, Wang D, Li SQ, Yu Y, Ye RD. Suppression of LPS-induced tau hyperphosphorylation by serum amyloid A. J Neuroinflammation. 2016:13:28

147. Roe AD, Staup MA, Serrats J, Sawchenko PE, Rissman RA. Lipopolysaccharide-induced tau phosphorylation and kinase activity-modulation, but not mediation, by corticotropin-releasing factor receptors. Eur J Neurosci. 2011;34:448-56.
148. Barron M Gartlon J Dawson LA Atkinson PJ, Pardon MC A state of delirium: deciphering the effect of inflammation on tau pathology in Alzheimer's disease. Exp Gerontol. 2017:94:103-7.

149. Rangasamy SB, Jana M, Roy A, Corbett GT, Kundu M, Chandra S, et al. Selective disruption of TLR2-MyD88 interaction inhibits inflammation and attenuates Alzheimer's pathology. J Clin Invest. 2018;128:4297-312.

150. Kim BW, Koppula S, Hong SS, Jeon SB, Kwon JH, Hwang BY, et al. Regulation of microglia activity by glaucocalyxin-A: attenuation of lipopolysaccharide-stimulated neuroinflammation through NF-kappaB and p38 MAPK signaling pathways. PLoS One. 2013;8:e55792.

151. McCarthy GM, Bridges CR, Blednov YA, Harris RA. CNS cell-type localization and LPS response of TLR signaling pathways. F1000Res. 2017:6:1144.

152. Mizobuchi H, Soma Gl. Low-dose lipopolysaccharide as an immune regulator for homeostasis maintenance in the central nervous system through transformation to neuroprotective microglia. Neural Regen Res. 2021;16:1928-34

153. Jendresen C, Digre A, Cui H, Zhang X, Vlodavsky I, Li JP, et al. Systemic LPS-induced Abeta-solubilization and clearance in AbetaPP-transgenic mice is diminished by heparanase overexpression. Sci Rep. 2019;9:4600.

154. Go M, Kou J, Lim JE, Yang J, Fukuchi KI. Microglial response to LPS increases in wild-type mice during aging but diminishes in an Alzheimer's mouse model: implication of TLR4 signaling in disease progression. Biochem Biophys Res Commun. 2016;479:331-7.

155. Quinn J, Montine T, Morrow J, Woodward WR, Kulhanek D, Eckenstein F. Inflammation and cerebral amyloidosis are disconnected in an animal model of Alzheimer's disease. J Neuroimmunol. 2003;137:32-41.

156. Thygesen C, Ilkjaer L, Kempf SJ, Hemdrup AL, von Linstow CU, Babcock AA, et al. Diverse protein profiles in CNS myeloid cells and CNS tissue from lipopolysaccharide- and vehicle-injected APPSWE/PS1DeltaE9 transgenic mice implicate Cathepsin Z in Alzheimer's disease. Front Cell Neurosci. 2018;12:397.

157. Piao W, Song C, Chen H, Diaz MA, Wahl LM, Fitzgerald KA, et al. Endotoxin tolerance dysregulates MyD88- and Toll/IL-1R domain-containing adapter inducing IFN-beta-dependent pathways and increases expression of negative regulators of TLR signaling. J Leukoc Biol. 2009;86:863-75.

158. Lee DC, Rizer J, Selenica ML, Reid P, Kraft C, Johnson A, et al. LPSinduced inflammation exacerbates phospho-tau pathology in rTg4510 mice. J Neuroinflammation. 2010;7:56.

159. Zhou J, Yu W, Zhang M, Tian X, Li Y, Lu Y. Imbalance of microglial TLR4/TREM2 in LPS-treated APP/PS1 transgenic mice: a potential link between Alzheimer's disease and systemic inflammation. Neurochem Res. 2019;44:1138-51.

160. Drake L, Scott P. Investigation into RAGE as a biomarker of the LPS-induced murine model of neuroinflammation. J Nucl Med. 2019:60:480-480.

161. Cai Z, Liu N, Wang C, Qin B, Zhou Y, Xiao M, et al. Role of RAGE in Alzheimer's disease. Cell Mol Neurobiol. 2016:36:483-95.

162. Fang F, Lue LF, Yan S, Xu H, Luddy JS, Chen D, et al. RAGE-dependent signaling in microglia contributes to neuroinflammation, Abeta accumulation, and impaired learning/memory in a mouse model of Alzheimer's disease. FASEB J. 2010:24:1043-55.

163. Wang L, Wu J, Guo X, Huang X, Huang Q. RAGE plays a role in LPSinduced NF-kappaB activation and endothelial hyperpermeability. Sensors (Basel). 2017;17:722

164. Loffredo L, Ettorre E, Zicari AM, Inghilleri M, Nocella C, Perri L, et al. Oxidative stress and gut-derived lipopolysaccharides in neurodegenerative disease: role of NOX2. Oxid Med Cell Longev. 2020;2020:8630275.

165. Zhang Y, Feng S, Nie K, Li Y, Gao Y, Gan R, et al. TREM2 modulates microglia phenotypes in the neuroinflammation of Parkinson's disease. Biochem Biophys Res Commun. 2018:499:797-802

166. Kim S, Chung H, Ngoc Mai H, Nam Y, Shin SJ, Park YH, et al. Low-dose ionizing radiation modulates microglia phenotypes in the models of Alzheimer's disease. Int J Mol Sci. 2020;21:4532.

167. Zhao J, Bi W, Xiao S, Lan X, Cheng X, Zhang J, et al. Neuroinflammation induced by lipopolysaccharide causes cognitive impairment in mice. Sci Rep. 2019;9:5790.

168. Sheppard O, Coleman MP, Durrant CS. Lipopolysaccharide-induced neuroinflammation induces presynaptic disruption through a direct 
action on brain tissue involving microglia-derived interleukin 1 beta. $J$ Neuroinflammation. 2019;16:1-13.

169. Abareshi A, Anaeigoudari A, Norouzi F, Shafei MN, Boskabady MH, Khazaei M, et al. Lipopolysaccharide-induced spatial memory and synaptic plasticity impairment is preventable by captopril. Adv Med. 2016;2016:1-8.

170. Xin Y, Jiang J, Hu Y, Pan J, Mi X, Gao Q, et al. Immune system drives synapse loss during LPS-induced learning and memory impairment in mice. Front Aging Neurosci. 2019;11:279.

171. Chugh D, Nilsson P, Afjei SA, Bakochi A, Ekdahl CT. Brain inflammation induces post-synaptic changes during early synapse formation in adultborn hippocampal neurons. Exp Neurol. 2013;250:176-88.

172. Zhan X, Stamova B, Sharp FR. Lipopolysaccharide associates with amyloid plaques, neurons and oligodendrocytes in Alzheimer's disease brain: a review. Front Aging Neurosci. 2018;10:42.

173. Xing B, Bachstetter AD, Van Eldik LJ. Microglial p38a MAPK is critical for LPS-induced neuron degeneration, through a mechanism involving TNFa. Mol Neurodegener. 2011;6:1-12.

174. Bachstetter AD, Xing B, de Almeida L, Dimayuga ER, Watterson DM, Van Eldik LJ. Microglial p38alpha MAPK is a key regulator of proinflammatory cytokine up-regulation induced by toll-like receptor (TLR) ligands or beta-amyloid (Abeta). J Neuroinflammation. 2011;8:79.

175. Qin L, Liu Y, Hong JS, Crews FT. NADPH oxidase and aging drive microglial activation, oxidative stress, and dopaminergic neurodegeneration following systemic LPS administration. Glia. 2013;61:855-68.

176. Ma MW, Wang J, Zhang Q, Wang R, Dhandapani KM, Vadlamudi RK, et al. NADPH oxidase in brain injury and neurodegenerative disorders. Mol Neurodegener. 2017;12:7.

177. Fragoso-Morales LG, Correa-Basurto J, Rosales-Hernandez MC. Implication of nicotinamide adenine dinucleotide phosphate (NADPH) oxidase and its inhibitors in Alzheimer's disease murine models. Antioxidants Basel. 2021;10:218.

178. Harland M, Torres S, Liu J, Wang X. Neuronal mitochondria modulation of LPS-induced neuroinflammation. J Neurosci. 2020;40:1756-65.

179. Khan MS, Muhammad T, Ikram M, Kim MO. Dietary supplementation of the antioxidant curcumin halts systemic LPS-induced neuroinflammation-associated neurodegeneration and memory/synaptic impairment via the JNK/NF-kappaB/Akt signaling pathway in adult rats. Oxid Med Cell Longev. 2019;2019:7860650

180. Li Y, Zhang L, Tang J, Yang X, Huang J, Zhu T, et al. Role of toll-like receptor 4 in the regulation of the cell death pathway and neuroinflammation. Brain Res Bull. 2019;148:79-90.

181. Yang $Y$, Wang H, Kouadir M, Song H, Shi F. Recent advances in the mechanisms of NLRP3 inflammasome activation and its inhibitors. Cell Death Dis. 2019;10:1-11.

182. Calvo-Rodriguez M, García-Rodríguez C, Villalobos C, Núñez L. Role of toll like receptor 4 in Alzheimer's disease. Front Immunol. 2020;11:1588.

183. Mattson M, Meffert M. Roles for NF-KB in nerve cell survival, plasticity, and disease. Cell Death Differ. 2006;13:852-60.

184. Angelucci F, Cechova K, Amlerova J, Hort J. Antibiotics, gut microbiota, and Alzheimer's disease. J Neuroinflammation. 2019:16:1-10.

185. Wang T, Hu X, Liang S, Li W, Wu X, Wang L, et al. Lactobacillus fermentum NS9 restores the antibiotic induced physiological and psychological abnormalities in rats. Benef Microbes. 2015;6:707-17.

186. Ribeiro CFA, Silveira G, Candido ES, Cardoso MH, Espinola Carvalho CM, Franco OL. Effects of antibiotic treatment on gut microbiota and how to overcome its negative impacts on human health. ACS Infect Dis. 2020;6:2544-59.

187. Balducci C, Santamaria G, La Vitola P, Brandi E, Grandi F, Viscomi AR, et al. Doxycycline counteracts neuroinflammation restoring memory in Alzheimer's disease mouse models. Neurobiol Aging. 2018;70:128-39.

188. Minter MR, Zhang C, Leone V, Ringus DL, Zhang X, Oyler-Castrillo P, et al. Antibiotic-induced perturbations in gut microbial diversity influences neuro-inflammation and amyloidosis in a murine model of Alzheimer's disease. Sci Rep. 2016;6:30028.

189. Loeb MB, Molloy DW, Smieja M, Standish T, Goldsmith CH, Mahony J, et al. A randomized, controlled trial of doxycycline and rifampin for patients with Alzheimer's disease. J Am Geriatr Soc. 2004;52:381-7.

190. Rezaei Asl Z, Sepehri G, Salami M. Probiotic treatment improves the impaired spatial cognitive performance and restores synaptic plasticity in an animal model of Alzheimer's disease. Behav Brain Res. 2019;376:112183.

191. Abraham D, Feher J, Scuderi GL, Szabo D, Dobolyi A, Cservenak M, et al. Exercise and probiotics attenuate the development of Alzheimer's disease in transgenic mice: role of microbiome. Exp Gerontol. 2019;115:122-31.

192. Nimgampalle M, Kuna Y. Anti-Alzheimer properties of probiotic, Lactobacillus plantarum MTCC 1325 in Alzheimer's disease induced albino rats. J Clin Diagn Res JCDR. 2017;11:KC01.

193. Akbari E, Asemi Z, Daneshvar Kakhaki R, Bahmani F, Kouchaki E, Tamtaji $\mathrm{OR}$, et al. Effect of probiotic supplementation on cognitive function and metabolic status in Alzheimer's disease: a randomized, double-blind and controlled trial. Front Aging Neurosci. 2016;8:256

194. Leblhuber F, Steiner K, Schuetz B, Fuchs D, Gostner JM. Probiotic supplementation in patients with Alzheimer's dementia-an explorative intervention study. Curr Alzheimer Res. 2018;15:1106-13.

195. Tamtaji OR, Heidari-Soureshjani R, Mirhosseini N, Kouchaki E, Bahmani F, Aghadavod E, et al. Probiotic and selenium co-supplementation, and the effects on clinical, metabolic and genetic status in Alzheimer's disease: a randomized, double-blind, controlled trial. Clin Nutr. 2019;38:2569-75

196. Agahi A, Hamidi GA, Daneshvar R, Hamdieh M, Soheili M, Alinaghipour $A$, et al. Does severity of Alzheimer's disease contribute to its responsiveness to modifying gut microbiota? A double blind clinical trial. Front Neurol. 2018;9:662.

197. Nagpal R, Neth BJ, Wang S, Mishra SP, Craft S, Yadav H. Gut mycobiome and its interaction with diet, gut bacteria and alzheimer's disease markers in subjects with mild cognitive impairment: A pilot study. EBioMedicine. 2020;59:102950.

198. Sun ZZ, Li XY, Wang S, Shen L, Ji HF. Bidirectional interactions between curcumin and gut microbiota in transgenic mice with Alzheimer's disease. Appl Microbiol Biotechnol. 2020;104:3507-15.

199. Park S, Kang S, Sol Kim D. Folate and vitamin B-12 deficiencies additively impaired memory function and disturbed the gut microbiota in amyloid-beta infused rats. Int J Vitam Nutr Res. 2019;1-13.

200. Guo Y, Wang L, Lu J, Jiao J, Yang Y, Zhao H, et al. Ginsenoside Rg1 improves cognitive capability and affects the microbiota of large intestine of tree shrew model for Alzheimer's disease. Mol Med Rep. 2021;23:291.

201. Bonfili L, Cecarini V, Berardi S, Scarpona S, Suchodolski JS, Nasuti C, et al. Microbiota modulation counteracts Alzheimer's disease progression influencing neuronal proteolysis and gut hormones plasma levels. Sci Rep. 2017;7:1-21.

202. Kim MS, Kim Y, Choi H, Kim W, Park S, Lee D, et al. Transfer of a healthy microbiota reduces amyloid and tau pathology in an Alzheimer's disease animal model. Gut. 2020;69:283-94.

203. Hazan S. Rapid improvement in Alzheimer's disease symptoms following fecal microbiota transplantation: a case report. J Int Med Res. 2020:48:300060520925930.

204. Dominy SS, Lynch C, Ermini F, Benedyk M, Marczyk A, Konradi A, et al. Porphyromonas gingivalis in Alzheimer's disease brains: evidence for disease causation and treatment with small-molecule inhibitors. Sci Adv. 2019:5:eaau3333.

205. Wang H, Lee IS, Braun C, Enck P. Effect of probiotics on central nervous system functions in animals and humans: a systematic review. J Neurogastroenterol Motil. 2016;22:589-605.

206. Wang T, Hu X, Liang S, Li W, Wu X, Wang L, et al. Lactobacillus fermentum NS9 restores the antibiotic induced physiological and psychological abnormalities in rats. Benef Microbes. 2015;6:707-17.

207. Chen D, Yang X, Yang J, Lai G, Yong T, Tang X, et al. Prebiotic effect of fructooligosaccharides from Morinda officinalis on Alzheimer's disease in rodent models by targeting the microbiota-gut-brain axis. Front Aging Neurosci. 2017;9:403.

208. D'Argenio V, Sarnataro D. Microbiome influence in the pathogenesis of prion and Alzheimer's diseases. Int J Mol Sci. 2019;20:4704.

209. Shabbir U, Arshad MS, Sameen A, Oh DH. Crosstalk between gut and brain in Alzheimer's disease: the role of gut microbiota modulation strategies. Nutrients. 2021;13:690.

210. Willett WC, Sacks F, Trichopoulou A, Drescher G, Ferro-Luzzi A, Helsing E, et al. Mediterranean diet pyramid: a cultural model for healthy eating. Am J Clin Nutr. 1995;61:1402S-1406S. 
211. Nagpal R, Neth BJ, Wang S, Craft S, Yadav H. Modified Mediterraneanketogenic diet modulates gut microbiome and short-chain fatty acids in association with Alzheimer's disease markers in subjects with mild cognitive impairment. EBioMedicine. 2019;47:529-42.

212. Costantini L, Molinari R, Farinon B, Merendino N. Impact of omega-3 fatty acids on the gut microbiota. Int J Mol Sci. 2017;18:2645.

213. La Rosa F, Clerici M, Ratto D, Occhinegro A, Licito A, Romeo M, et al. The gut-brain axis in Alzheimer's disease and omega-3. A critical overview of clinical trials. Nutrients. 2018:10:1267.

214. Bonfili L, Cecarini V, Berardi S, Scarpona S, Suchodolski JS, Nasuti C, et al. Microbiota modulation counteracts Alzheimer's disease progression influencing neuronal proteolysis and gut hormones plasma levels. Sci Rep. 2017;7:2426

215. Kim MS, Kim Y, Choi H, Kim W, Park S, Lee D, et al. Transfer of a healthy microbiota reduces amyloid and tau pathology in an Alzheimer's disease animal model. Gut. 2020;69:283-94.

216. Hazan S. Rapid improvement in Alzheimer's disease symptoms following fecal microbiota transplantation: a case report. J Int Med Res. 2020;48:0300060520925930.

217. DeFilipp Z, Bloom PP, Torres Soto M, Mansour MK, Sater MRA, Huntley $\mathrm{MH}$, et al. Drug-resistant E. coli bacteremia transmitted by fecal microbiota transplant. N Engl J Med. 2019;381:2043-50,

Ready to submit your research? Choose BMC and benefit from:

- fast, convenient online submission

- thorough peer review by experienced researchers in your field

- rapid publication on acceptance

- support for research data, including large and complex data types

- gold Open Access which fosters wider collaboration and increased citations

- maximum visibility for your research: over $100 \mathrm{M}$ website views per year

At BMC, research is always in progress.

Learn more biomedcentral.com/submissions 